\title{
Contribuciones metodológicas para valorar la multifuncionalidad de la agricultura campesina en la Meseta Purépecha
}

\section{Methodological contributions to evaluate the farming agricultural multi-functionality in the Purépecha plateau.}

\author{
Dante Ariel Ayala-Ortiz* \\ RAÚl GARCÍA-BARRIOS**
}

\begin{abstract}
This paper offers an analysis of the farming Multi-functionality of agriculture (MFA) in the Purépecha plateau of Michoacán (Mexico) in order to identify some of its components and contribute to the development of an adequate methodology for its evaluation. Among the methodological innovations proposed we emphasise the methods developed in order to: 1) estimate the supply of marketless goods from contingent evaluation schemes, 2) approximate the evaluation of quality of life and 3) measure the diversification risk in the income of rural households.
\end{abstract}

Palabras clave: externalities, public goods, sustainable rual development, farming policy.

\section{Resumen}

En este artículo se ofrece un análisis de la multifuncionalidad de la agricultura (MFA) campesina en la Meseta Purépecha de Michoacán (México), con el objetivo de identificar algunos de sus componentes y contribuir al desarrollo de una metodología adecuada para su valoración. Entre las innovaciones metodológicas propuestas destacan los métodos desarrollados para: 1) estimar oferta de bienes sin mercados a partir de esquemas de valoración contingente; 2) aproximarse a evaluar la calidad de vida, y 3) medir la diversificación del riesgo en el ingreso de hogares rurales.

Palabras clave: externalidades, bienes públicos, desarrollo rural sustentable, política agrícola.

\footnotetext{
* Universidad Michoacana de San Nicolás de Hidalgo, México. Correo-e: dante ariel12@yahoo.com.mx.

** Universidad Nacional Autónoma de México, México. Correo-e: rgarciab@servidor.unam.mx.
} 


\section{Introducción}

Era frecuente que las funciones de la agricultura se reconocieran en términos de la provisión de alimentos, fibras y otras materias primas, el efecto en los precios de éstos, la aportación de trabajo y capital y la constitución de un mercado para el consumo de bienes no agrícolas (Valdés y Foster, 2004: 3). Sin embargo, hace algunos años surgió otra perspectiva que considera a la agricultura como proveedora de otras funciones no económicas, como la seguridad alimentaria, la conservación del medio ambiente y del paisaje rural, y como algo que contribuye a la viabilidad de las áreas rurales al proveer fuentes de ocupación y favorecer un desarrollo territorial equilibrado (Crecente, 2002).

La multifuncionalidad de la agricultura (MFA) se refiere a las propiedades específicas de esta actividad productiva y al hecho de que pueda generar diversos productos y con ello contribuir en la realización de múltiples objetivos (OECD, 2001: 6; Losch, 2002).

Un elemento esencial en el estudio de la MFA es la conceptualización de esta actividad como un proceso de producción conjunta, es decir, un proceso en el que existen dos o más productos técnicamente interdependientes, como la producción de bienes comerciales (alimentos y materias primas que constituyen la motivación primaria de la actividad) y productos no comerciales que se generan junto con los primeros (OECD, 2001: 27). Entre las múltiples funciones que la agricultura cumple o debe cumplir, se destacan las que se señalan en el cuadro 1.

Desde el punto de vista metodológico, Losch menciona que la MFA es un concepto afín con la noción de desarrollo y sustentabilidad, por lo que se le puede considerar como "la operacionalización del modelo de la agricultura sustentable" (2002: 4). De hecho, Hagedorn (2005) concibe la multifuncionalidad como una herramienta para incrementar la sustentabilidad de una determinada actividad.

En la actualidad contamos con pocas experiencias concretas, sistemáticas y consistentes para hacer operativos los principios en los que se basa la MFA. En el aspecto teórico, uno de los principales trabajos que se han realizado es el que desarrolló la Organización para la Cooperación y el Desarrollo Económico (2001) al establecer un marco analítico sobre la multifuncionalidad, y al argumentar las implicaciones de política sobre el mismo concepto (OECD, 2003). 


\section{Cuadro 1 \\ Funciones y roles múltiples de la agricultura por ámbito de incidencia}

\begin{tabular}{|c|c|}
\hline $\begin{array}{l}\text { Carácter } \\
\text { ambiental }\end{array}$ & $\begin{array}{l}\text { Proveer servicios ambientales valiosos: como abastecimiento } \\
\text { regular de agua limpia, reducción de riesgos por sequías, } \\
\text { inundaciones o avalanchas, y preservación de la diversidad } \\
\text { biológica } \\
\text { Asegurar la diversidad del paisaje y preservar el } \\
\text { patrimonio natural } \\
\text { Favorecer prácticas agrícolas respetuosas con el medio } \\
\text { ambiente } \\
\text { Contribuir a proporcionar al ciudadano una red de } \\
\text { espacios naturales }\end{array}$ \\
\hline $\begin{array}{l}\text { Carácter } \\
\text { sociocultural }\end{array}$ & $\begin{array}{l}\text { Proteger las unidades de producción familiares de } \\
\text { pequeña escala } \\
\text { Salvaguardar la riqueza cultural y las múltiples } \\
\text { identidades regionales } \\
\text { Conservar paisajes rurales tradicionales } \\
\text { Preservar productos, costumbres y cultura rural tradicionales } \\
\text { Mantener el empleo y el ingreso adecuados en el medio rural } \\
\text { Proporcionar identidad y sentido de pertenencia a escalas } \\
\text { local y regional }\end{array}$ \\
\hline $\begin{array}{l}\text { Carácter } \\
\text { económico- } \\
\text { productivo }\end{array}$ & $\begin{array}{l}\text { Proveer bienes intercambiables con otros sectores, así como } \\
\text { generar excedentes exportables que aporten divisas a la } \\
\text { economía } \\
\text { Asegurar que los alimentos sean sanos y saludables } \\
\text { Mantener un grado adecuado de autoabastecimiento } \\
\text { alimentario } \\
\text { Fortalecer la economía contra los riesgos externos }\end{array}$ \\
\hline $\begin{array}{l}\text { Carácter } \\
\text { territorial }\end{array}$ & $\begin{array}{l}\text { Garantizar la soberanía del país y el fortalecimiento del } \\
\text { mercado interno } \\
\text { Contribuir a la viabilidad de las áreas rurales y a un desarrollo } \\
\text { territorial equilibrado interactuando con otras actividades } \\
\text { Ofrecer un espacio sano para que allí resida una importante } \\
\text { parte de la población y se descongestionen las ciudades }\end{array}$ \\
\hline
\end{tabular}

Fuente: Kallas y Gómez-Limón (2005); Valdés y Foster (2004); OECD (2001).

Diversos países (como Corea, Japón, Suiza, Francia y otros miembros de la Unión Europea) ya reconocieron la naturaleza multifuncional de la agricultura en su marco normativo oficial. En el año 2003, por medio del llamado Acuerdo Nacional para el Campo, México estableció como principio rector del Acuerdo el "reconocimiento del carácter multifuncional de la agricultura y del derecho de los campesinos e indígenas a preservar y mejorar sus formas de producción, revalorando así la capacidad de desarrollo de las agriculturas campesina e indígena (Sagarpa, 2003: 10). Sin embargo, hasta ahora esto no ha pasado de ser sólo una 
declaración que aún no ha encontrado su expresión concreta en las medidas de política pública del sector.

En tal contexto, éste es un trabajo sobre la agricultura campesina y la estimación de su MFA. El presente estudio es el primero de una investigación más amplia, que tiene como objetivo central presentar algunos instrumentos metodológicos propios desarrollados para la estimación de la MFA campesina, tomando como estudio de caso a la región conocida como Meseta Purépecha, en el occidente de México, misma que seleccionamos como sitio apropiado para la investigación considerando que, en términos generales, es posible encontrar en ella localidades que aún conservan importantes rasgos indígenas (como lengua autóctona, cosmovisión, gastronomía y prácticas agrícolas tradicionales), pero también localidades primordialmente mestizas.

Debido a que la multifuncionalidad es una cuestión de grado (como de no presencia-ausencia), a partir de los resultados obtenidos con esta metodología elaborada por nosotros, se realizaron análisis comparativos de la MFA entre sistemas de producción campesino indígena con respecto a un sistema campesino no indígena. En esta primera aproximación al objeto de estudio, con la metodología desarrollada sólo se pretende describir de manera comparativa el comportamiento de los componentes de la MFA y saber si existen diferencias estadísticamente significativas entre los grupos en cuestión. En términos del estudio comparativo, la hipótesis que guía esta investigación sostiene que las comunidades de origen mestizo observan una mayor provisión de funciones de carácter ambiental y sociocultural con respecto a las mestizas, en tanto que estas últimas aportan más funciones de carácter económico. No obstante, es preciso señalar que la explicación de asociación y causalidad de las diferencias observadas será propósito de una segunda investigación.

En general, el conjunto de indicadores propuestos para evaluar los componentes de la MFA mostraron suficiente solidez estadística y sensibilidad al cambio, por lo que se pueden considerar apropiados. Sin embargo, se observa que en la medida que se hace una mayor agregación de la información (por ejemplo, conjuntar varios indicadores para construir una variable o diversas variables para integrar un atributo), las diferencias muestrales se van diluyendo y hacen que cada vez los resultados tiendan a mostrar valores de diferencia estadística no significativos, lo que recomienda mantener el análisis de estos componentes por separado. 


\section{Metodología}

\subsection{Descripción del sitio}

La Meseta Purépecha central se ubica en la porción centro-occidente del estado de Michoacán (figura I), es una zona bordeada por serranías que forman parte del Sistema Volcánico Transversal, cuenta con extensos bosques de pino y encino que dan lugar a un clima templado de húmedo a subhúmedo, con suelos principalmente andosólicos (Escobar et al., 1997: 66) que por su origen cenizo limitan el uso agrícola sólo a ciertas variedades de cultivos localmente desarrolladas. La mayoría de las familias en la región se dedican sobre todo a la producción de maíz de temporal relacionada con la engorda de algunos animales, con un promedio de 5 ha por agricultor (aunque la moda es 2 ha, de acuerdo con información proveniente de la base de datos de productores inscritos en el programa Procampo y observaciones propias), que siembran primordialmente bajo el régimen de propiedad social (aunque existen otras parcelas con superficies de 20 a 30 ha en régimen de pequeña propiedad privada) y utilizan casi invariablemente la semilla criolla seleccionada por ellos.

De acuerdo con el régimen de humedad en el que se cultiva y la altitud media de los valles agrícolas de la zona $(2,300 \mathrm{msnm})$, la agricultura que se practica en la mayor parte de la Meseta Purépecha central es mediante el sistema temporal de humedad residual (Romero, 1995: 71), que se caracteriza porque el suelo conserva gran parte de la humedad acumulada durante la época fría del año (de noviembre a febrero), lo cual permite que la siembra se realice antes de la temporada de lluvias (mayo a septiembre).

Hace medio siglo esta región aún se distinguía por su relativo grado de autosuficiencia para proveerse de los elementos materiales y culturales necesarios para dar sostén y viabilidad a su tradicional organización comunitaria, teniendo al maíz como la base de su actividad y su vínculo con otras labores productivas (Beals, 1992: 60), así como al uso múltiple y sustentable de su entorno natural.

Sin embargo, su creciente interrelación con la sociedad no purépecha y su inclusión en los esquemas desarrollistas gubernamentales probablemente transformaron esta cultura, pues la condujeron a la pérdida de su ancestral capital social, ambiental, económico y cultural. Es de suponer que al romperse la producción de maíz como eje articulador de las actividades económicas 
Figura I

Localización del sitio de estudio: Meseta Purépecha central

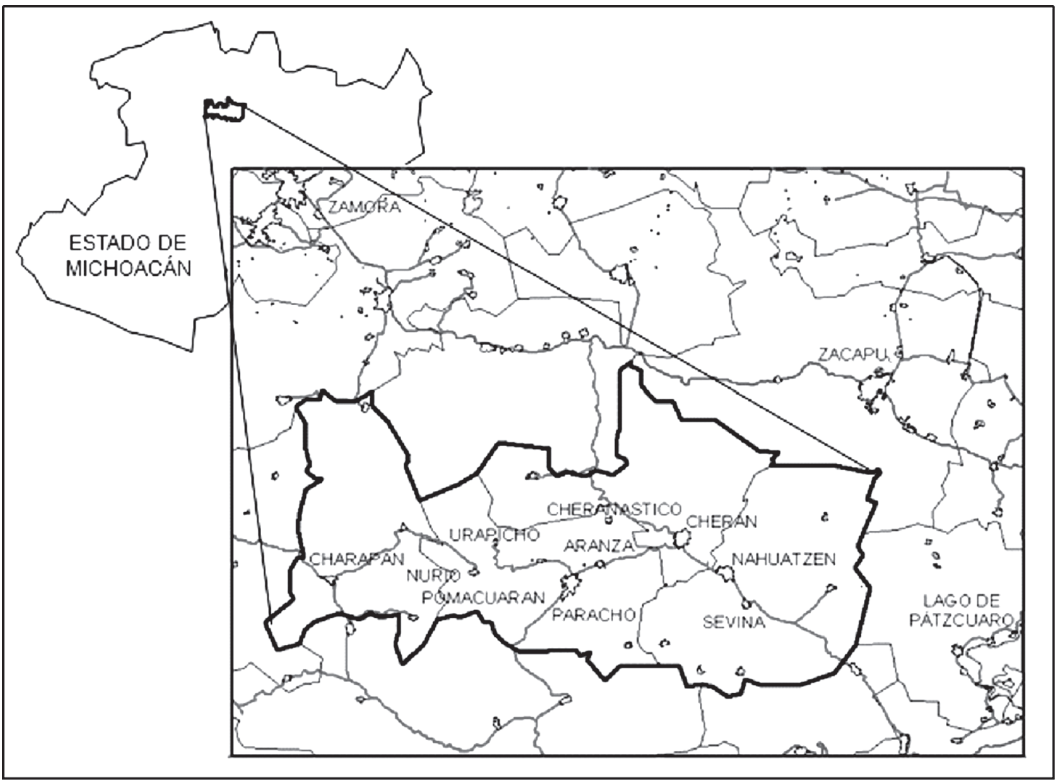

en la región (Ayala, 2007: 200; Alarcón, 2001: 223), se fueron reduciendo muchas de las funciones que otrora cumplía la agricultura campesina en la zona purépecha.

\subsection{Métodos}

Se combinaron herramientas y perspectivas analíticas de tres distintas fuentes: 1) el marco teórico-metodológico sobre MFA de la OECD $(2001,2003)$; 2) el instrumental básico del llamado diagnóstico y desarrollo rural participativo, impulsado por el Instituto Interamericano de Cooperación para la Agricultura (Geilfus, 1997); y 3) el marco para la evaluación de sistemas de manejo incorporando indicadores de sustentabilidad (MESMIS), propuesto por el Grupo Interdisciplinario de Tecnología Rural Apropiada (GIRA, A.C.) (Masera et al., 2000).

Ya que la MFA ambiental es el concepto clave del estudio, lo analizamos identificando en cada uno de sus componentes las funciones o roles que se consideraron significativos para evaluar desde el principio. A su vez, cada una de estas funciones se identificó con un atributo cuyo efecto resultara de particular relevancia para el sistema (como agrobiodiversidad, sustentabilidad y calidad de 
vida). En total se identificaron nueve atributos relevantes, mismos que se desglosaron en un total de 18 variables de impacto, es decir, aquéllas con las cuales se evaluaría el sistema integral (Anexo 1). Finalmente, cada variable se operacionalizó mediante un indicador o un conjunto de indicadores (Anexo 2). Se debe señalar que, en la mayoría de los casos, esto último se hizo a partir de indicadores empíricos construidos expresamente en esta investigación, cuidando la facilidad de cálculo y medición, así como su sensibilidad al cambio en la propiedad que se mide.

Entre noviembre de 2005 y mayo de 2006 se realizaron 15 entrevistas a informantes clave (representantes de la comunidad o de sus organizaciones, líderes naturales, regidores de agricultura, entre otros). Después, de mayo a agosto de 2006, se levantó una encuesta considerando dos comunidades predominantemente indígenas (Cheranatzicurin y Urapicho), y otras dos no indígenas (Aranza y Pomacuarán), que se diferenciaron en lo fundamental con base en el uso primordial de la lengua autóctona como rasgo distintivo de indigenismo. En cada una de ellas se realizó un total de 20 aplicaciones $(n=80)$, de las cuales 10 fueron aleatorizadas a partir del marco muestral de Procampo y las otras 10 del listado de productores usuarios de lombricomposta.

Con el propósito de determinar si hay diferencias estadísticamente significativas entre los sistemas de producción comparados (por ejemplo, sistema campesino indígena $v$ s. sistema campesino no indígena), y dada la naturaleza del esquema de muestreo, tamaño del mismo y tipo de variables incluidas en el estudio (muchas de ellas categóricas), se optó por utilizar un método estadístico no paramétrico conocido como Prueba $U$ de Mann-Whitney (U de M-W), que permite determinar si dos muestras independientes provienen de una misma población, es decir, si el valor calculado de una variable es equivalente en su posición en ambas muestras (Mendenhal y Reinmuth, 1999: 590-599).

\section{Resultados y discusión}

A continuación se presentan los cálculos que se hicieron y sus resultados, se analizó cada una de las funciones que se consideraron relevantes según el componente (por ejemplo, ambiental, sociocultural y económico) y al final se hizo un balance general sobre la MFA. Es preciso señalar que los atributos y variables aquí incluidos de ninguna forma son exhaustivos con respecto al am- 
plio concepto de la MFA, por lo que su análisis y discusión sólo es una contribución más a su entendimiento y valoración.

\subsection{Multifuncionalidad ambiental}

En la interacción continua entre agricultura y medio ambiente existen cuantiosas relaciones que desembocan en la formación de un importante número de bienes públicos (como preservación de la biodiversidad, prevención de riesgos naturales, captura de gases de efecto invernadero) y en la generación de externalidades negativas (contaminación y agotamiento de cuerpos de agua, erosión y pérdida de la fertilidad del suelo, fragmentación del hábitat, etcétera).

En este caso, el análisis se concentra fundamentalmente en la provisión de los servicios ambientales y bienes públicos que se consideran positivos para el entorno y la sociedad, puesto que, como demostraron Kallas y Gómez-Limón -quienes realizaron un estudio de caso sobre multifuncionalidad en Castilla y León, España-, se ha encontrado que las externalidades ambientales negativas son "cuantitativamente mucho menos significativas que las positivas” (2005: 11), y están muy localizadas en aquellas zonas de agricultura intensiva, como la de riego. En tal virtud, al no estar presente el sistema de riego en el sitio de estudio de esta tesis, se optó por considerar únicamente las externalidades positivas.

En este trabajo se propone una concepción propia de la multifuncionalidad ambiental, y se le define como la capacidad del sistema para proveer diversos servicios, bienes públicos y externalidades de índole ambiental a partir de la actividad agrícola campesina. En el cuadro 2 se observan los resultados de tres funciones que se consideraron importantes para analizar en este componente: 1) preservación de la diversidad biológica del sistema agrícola; 2) empleo de prácticas agrícolas sustentables; y 3) autosuficiencia de recursos genéticos y energéticos.

\subsubsection{Función 1: preservación de la diversidad biológica del siste- ma agrícola}

Este atributo lo integran dos variables: la diversidad agrobiológica del maíz y la diversidad agroambiental. En el caso de la primera, se adaptó el índice de diversidad de Shannon (H'), el cual se basa no sólo en la riqueza sino también en la abundancia de las especies encontradas en una determinada unidad de estudio 
(Magurran, 1988: 34). Para aplicarlo a la medición de la diversidad biológica del maíz criollo, se consideró la superficie de cultivo de cada variedad como una variable proxy de la abundancia.

Usualmente en la estimación de la diversidad biológica los valores del índice de Shannon fluctúan de 1.5 a 3.5 unidades; en este caso, los resultados encontrados fueron de 0.57 y 0.53 para los sistemas indígena y no indígena, respectivamente. Lo anterior se puede deber al gran peso relativo que tiene la siembra de las variedades de maíz criollo blanco con respecto a las variedades de color, de allí que al ser éste un índice que pondera significativamente la proporcionalidad (eveness) en la representación de las especies, el valor de H' haya salido relativamente bajo.

Además se debe destacar que no se encontró diferencia estadísticamente significativa entre estos valores según la Prueba U de M-W, lo cual refleja que, con respecto a la variable diversidad agrobiológica del maíz, los productores campesinos tanto de las comunidades indígenas como de las no indígenas se comportan bajo un patrón similar de siembra de variedades criollas.

Por otra parte, dos de los tres indicadores que componen la variable diversidad agroambiental (riqueza total y fragmentación del hábitat) no mostraron diferencias notables, únicamente el indicador diversidad de hábitat maicero, el cual considera la práctica de técnicas agrícolas que dan sustento a una mayor diversidad agroambiental (como el policultivo), resultó significativo ( $p<0.05)$.

En general los sistemas de policultivos son comunes entre los productores campesinos y se practican en diferentes composiciones vegetales, pero son mucho más frecuentes en las comunidades de tipo indígena (58.2\%), en las cuales es usual que el maíz se asocie con calabaza y frijol, y ocasionalmente se acompaña o rota con habas (cuadro 3 ).

En el caso de las comunidades no indígenas existe una mayor tendencia hacia el monocultivo (64.8\%), en virtud de que han estado más abiertas a adoptar los modelos agronómicos productivistas de la Revolución Verde y a que en ellos también existe una mayor inclinación hacia la producción orientada al mercado.

En conjunto, no se advirtieron diferencias significativas entre las comunidades indígenas y no indígenas en la función relativa a la preservación de la diversidad biológica agrícola (cuadro 2). 


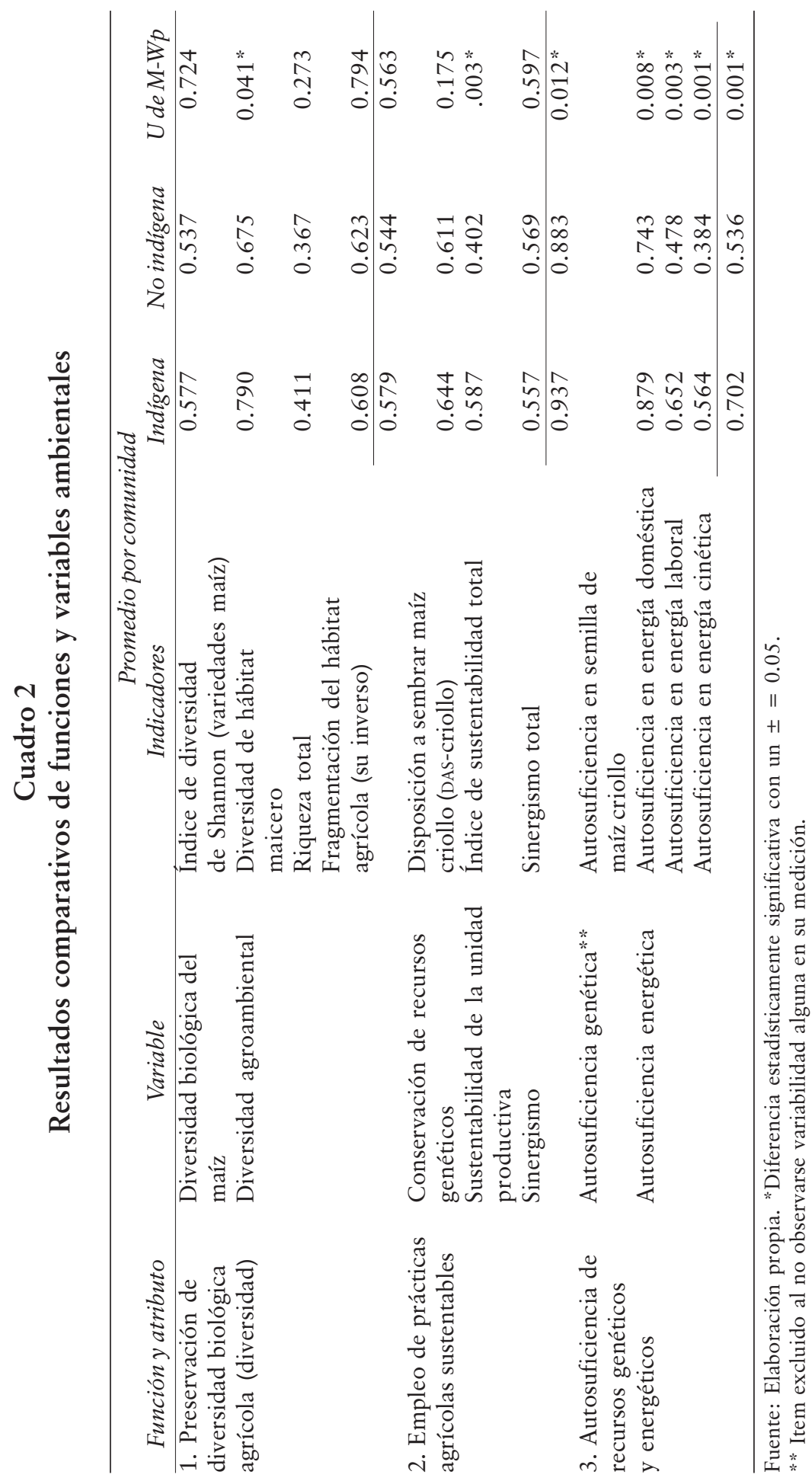




\section{Cuadro 3}

Porcentaje de unidades con práctica de policultivo por tipo de comunidad

\begin{tabular}{llccc}
\hline & & \multicolumn{2}{c}{ Policultivo } & \\
& & No & Sí & Total \\
\hline Comunidad & Indígena & 41.8 & 58.2 & $100 \%$ \\
& No indígena & 64.8 & 35.2 & $100 \%$ \\
\hline
\end{tabular}

Fuente: Elaboración propia.

\subsubsection{Función 2: empleo de prácticas agrícolas sustentables}

La sustentabilidad es un concepto que tiene la particularidad de que es altamente operacional y medible, y al mismo tiempo, muy abstracto y extenso. En este estudio la sustentabilidad se refiere a la capacidad del sistema agrícola para hacer frente a perturbaciones y cambios mayores en el transcurso del tiempo, regresa a su estabilidad original, hace uso renovable y múltiple de los recursos naturales y tecnológicos disponibles, y propicia su conservación y uso sinérgico.

Para evaluar las prácticas sustentables se emplearon tres variables definidas internamente. La conservación de recursos genéticos del maíz se estimó a partir de un esquema de valoración contingente que permitió conocer la disposición a sembrar (diferentes variedades de maíz), bajo el supuesto de disponer 10 ha de tierra para este cultivo.

En la región purépecha es posible encontrar una enorme diversidad de variedades de maíz que se distinguen por su color azul (tziri uaroti), negro o morado (tziri turipiti), amarillo (tsiri tsipambiti), rojo (tziri charapiti), blanco (tziri urapiti), pinto azul (huapaz), pinto rojo (chochu), pinto negro y rojo (jaripo), entre otros.

Las pruebas realizadas demostraron que no hay diferencias estadísticamente significativas en la disposición a sembrar variedades de maíces criollos blanco, azul, amarillo y rojo entre las comunidades indígenas y no indígenas ( $\mathrm{p}<0.05)$, excepto para el caso de la siembra del maíz morado o negro (tziri turipiti), al cual las comunidades indígenas le asignaron una mayor superficie (cuadro 4). Este resultado es consistente con el hecho de que este tipo de maíz es muy valorado en la gastronomía autóctona purépecha $y$, por tanto, se presenta una mayor proclividad a su siembra en estas poblaciones. 


\section{Cuadro 4}

Disposición a sembrar maíz criollo (DAS-criollo): promedio sobre 10 ha

\begin{tabular}{llccc}
\hline $\begin{array}{c}\text { Variedad } \\
\text { de maíz }\end{array}$ & Comunidad & $\begin{array}{c}\text { DAs-criollo } \\
(\mathrm{Ha} \text { prom } / 10)\end{array}$ & $\begin{array}{c}\text { Desviación } \\
\text { estándar }\end{array}$ & Ude M-Wp \\
\hline Blanco & Indígena & 5.95 & 1.55 & 0.856 \\
\multirow{4}{*}{ Azul } & No indígena & 5.56 & 2.24 & \\
& Indígena & 2.10 & 1.22 & 0.868 \\
Amarillo & No indígena & 2.36 & 1.85 & \\
\multirow{4}{*}{ Morado/negro } & Indígena & 1.00 & 0.96 & 0.098 \\
\multirow{2}{*}{ Rojo } & No indígena & 1.49 & 1.54 & \multirow{2}{*}{ Indígena } \\
& No indígena & 0.76 & 0.46 & \\
& Indígena & 0.52 & 0.43 & \multirow{2}{*}{0.109} \\
\hline
\end{tabular}

Fuente: Elaboración propia.

"Diferencia estadísticamente significativa con un $\pm=0.05$.

La alta disposición a sembrar las variedades de maíces blan$\cos (59.5 \%$ y $55.6 \%)$ se atribuye a que la mayoría de los platillos gastronómicos de la región toman como base los maíces de esta coloración, y a que, si existe la posibilidad de vender excedentes de la cosecha, la principal demanda que se encontrará será por maíces de este color.

Tanto el maíz azul como el negro son variedades que se mezclan en bajas proporciones dentro del mismo cultivo del maíz blanco; en el caso del maíz azul se observó que en las comunidades no indígenas existe una mayor disposición a sembrarlo, dado que han encontrado un mercado regional importante y mejor pagado, en virtud que este maíz es mucho más apreciado para su consumo en elote (se estimó que la venta del producto en esta presentación casi puede triplicar el ingreso del producto con respecto a la venta del maíz blanco en grano).

Por otra parte, la valoración de la sustentabilidad de la unidad productiva se estimó a partir de la integración de cuatro áreas: 1) la calidad y cantidad de insumos para la producción; 2) el tipo de maquinaria e implementos agrícolas empleado; 3) el manejo agronómico del sistema agrícola; y 4) el manejo organizacional de la unidad productiva. En las cuatro áreas evaluadas se observaron valores de mayor sustentabilidad para el caso de las comunidades indígenas en un grado significativamente mayor que en las no indígenas ( $\mathrm{p}<0.05$; cuadro 5$)$. 


\section{Cuadro 5}

Índices de sustentabilidad promedio por área de evaluación

\begin{tabular}{|c|c|c|c|c|}
\hline $\begin{array}{c}\text { Área de } \\
\text { sustentabilidad } \\
\text { evaluada }\end{array}$ & Comunidad & $\begin{array}{c}\text { Indice de } \\
\text { sustentabilidad } \\
\text { promedio }\end{array}$ & $\begin{array}{c}\text { Desviación } \\
\text { estándar }\end{array}$ & $U$ de $M-W p$ \\
\hline \multirow[t]{2}{*}{ Insumos } & Indígena & 0.1558 & 0.09247 & \multirow[t]{2}{*}{$0.000 *$} \\
\hline & No indígena & 0.0574 & 0.10878 & \\
\hline \multirow[t]{2}{*}{$\begin{array}{l}\text { Equipo e } \\
\text { implementos }\end{array}$} & Indígena & 0.4062 & 0.33372 & \multirow[t]{2}{*}{$0.032 *$} \\
\hline & No indígena & 0.2628 & 0.34209 & \\
\hline \multirow[t]{2}{*}{$\begin{array}{l}\text { Manejo } \\
\text { agronómico }\end{array}$} & Indígena & 0.7065 & 0.17899 & \multirow[t]{2}{*}{$0.001 *$} \\
\hline & No indígena & 0.5370 & 0.21351 & \\
\hline \multirow[t]{2}{*}{$\begin{array}{l}\text { Manejo } \\
\text { organizacional }\end{array}$} & Indígena & 0.5905 & 0.09127 & \multirow[t]{2}{*}{$0.001 *$} \\
\hline & No indígena & 0.5051 & 0.11476 & \\
\hline
\end{tabular}

Fuente: Elaboración propia.

*Diferencia estadísticamente significativa con un $\pm=0.05$.

Ambos grupos de comunidades resultaron bajos en la sustentabilidad de los insumos aplicados, pues comparando el tipo de abonos, fertilizantes o controladores de arvenses, en todos los casos fue frecuente el carácter fuertemente degradante de los fertilizantes y herbicidas agroquímicos.

En el caso del área de equipo e implementos, aunque también son bajos los promedios en ambos grupos, las comunidades indígenas mostraron un mejor resultado debido a que en ellas todavía es más común el uso de equipo e implementos relacionados con la tracción animal, que técnicamente se consideran menos degradantes del suelo que los de tracción mecánica.

Para el análisis del manejo agronómico se consideró la forma de cultivo, el mejoramiento de la fertilidad del suelo, el control de arvenses, la cosecha y el almacenamiento; las comunidades indígenas nuevamente mostraron un manejo más sustentable en este rubro. Resultados similares se observaron en el área del manejo organizacional que evaluó aspectos como la complementariedad de la agricultura con otras labores, el empleo y aprovechamiento de la mano de obra y la transferencia del conocimiento de la práctica agrícola. Así, la segunda variable de esta función fue mucho mayor para las comunidades indígenas (cuadro 2).

Una tercera variable relacionada con la sustentabilidad fue el sinergismo, que considera la participación de la unidad de producción campesina en actividades agrícolas, pecuarias y forestales bajo relaciones de interdependencia (como flujos de materia 


\section{Cuadro 6 \\ Unidades campesinas que participan en diferentes actividades sinérgicas \\ (porcentaje)}

\begin{tabular}{|c|c|c|c|c|c|c|}
\hline & \multicolumn{5}{|c|}{ Sinergismo } \\
\hline & & $\begin{array}{c}\text { Agrope- } \\
\text { cuario }\end{array}$ & $\begin{array}{c}\text { Agrofo- } \\
\text { restal }\end{array}$ & $\begin{array}{c}\text { Silvope- } \\
\text { cuario }\end{array}$ & $\begin{array}{l}\text { Agrosilvo- } \\
\text { pecuario }\end{array}$ & $\begin{array}{l}\text { Ninguno } \\
\text { (sólo agri- } \\
\text { cultura) }\end{array}$ \\
\hline \multirow[t]{2}{*}{ Comunidad } & Indígena & 34.9 & 7.0 & 0.0 & 20.9 & 37.2 \\
\hline & No indígena & 37.8 & 8.1 & 0.0 & 24.3 & 29.7 \\
\hline
\end{tabular}

Fuente: Elaboración propia.

y energía entre la agricultura, la ganadería y la forestería) y sustentabilidad entre éstas. Los resultados no mostraron diferencias importantes entre las comunidades comparadas, como se observa en los cuadros 2 y 6 .

A partir de estos resultados, se observa que en la función empleo de prácticas agrícolas sustentables en su conjunto sí existen diferencias estadísticamente significativas $(\mathrm{p}<0.05)$, que se pueden asociar al carácter indígena o no de las comunidades en comparación (cuadro 2), aunque esta asociación no se debe interpretar como determinante.

\subsubsection{Función 3: autosuficiencia de recursos genéticos y energéticos}

En este trabajo autosuficiencia se refiere al potencial del sistema campesino para proveerse a sí mismo las semillas e insumos energéticos necesarios para la actividad agrícola; cada uno de estos rubros son las variables que se tomaron en cuenta para medir esta función.

La autosuficiencia genética se propuso particularmente para la siembra de maíz, considerando la selección de semillas a partir de granos producidos en cosecha propia como el valor deseado frente a la obtención de este insumo mediante fuentes externas a la unidad de producción (valor no deseado). En la práctica, los datos recopilados mostraron que en la totalidad de las unidades muestreadas se utiliza semilla criolla seleccionada a partir de la cosecha propia, por lo que evidentemente este concepto no mostró variabilidad dentro de la muestra, pues se comportó como una constante y limitó su uso para fines estadísticos. No obstante, se considera que este concepto podrá mostrar comportamientos significativos cuando se use para la comparación entre siste- 
mas de producción menos similares y tradicionales que los que se consideran aquí.

En el caso de la autosuficiencia energética se incluyeron tres áreas de evaluación: 1) energía doméstica; 2) energía laboral (por ejemplo, para preparar terreno, siembra, laboreo, etc.) y 3) energía cinética (para transporte familiar y laboral). En los tres casos los resultados (cuadro 2) muestran valores de mayor autosuficiencia en las comunidades indígenas con una diferencia estadísticamente significativa $(\mathrm{p}<0.05)$. Esto se explica porque si bien tanto en las comunidades indígenas como no indígenas predomina el uso de leña para las labores domésticas de cocción y calefacción, en el caso de las primeras lo común es que se abastezcan mediante la colecta directa, mientras que en las segundas es frecuente recurrir a la compra de leña. Algo similar sucede con la autosuficiencia energética para el trabajo (laboral) y el transporte (cinética), dado que en ambos rubros es común que los campesinos de comunidades no indígenas utilicen tracción mecánica a base de gasolina, lo que implica la compra de este insumo energético, mientras que en las comunidades indígenas aún prevalece la tracción animal y humana para estos propósitos.

\subsection{Multifuncionalidad sociocultural}

Este componente de la multifuncionalidad se refiere a la facultad del sistema campesino para desempeñar roles o generar servicios y bienes de carácter sociocultural que se desprenden de su actividad agrícola. Entre estas funciones se consideraron: 4) incremento de capacidades para lograr funcionamientos valiosos; 5) sostenimiento de empleo rural; y 6) fortalecimiento de la soberanía alimentaria rural.

\subsubsection{Función 4: incremento de capacidades para lograr funcio- namientos valiosos (atributo: calidad de vida)}

Esta función se estudió desde la perspectiva teórica de Amartya Sen, para quien existe una relación directa entre funcionamientos valiosos, capacidades y calidad de vida. Los funcionamientos representan partes del estado de una persona, como las cosas que logra hacer o ser al vivir, y es la capacidad un reflejo de las combinaciones alternativas de funcionamientos que esta persona puede lograr y entre las cuales puede elegir. Relacionando este concepto con la noción de Sen (1998: 55) de calidad de vida, 
ésta se evalúa en términos de la capacidad para lograr funcionamientos valiosos.

Así, el número de opciones que las personas tienen y la libertad de elección sobre éstas también contribuyen al bienestar humano de manera directa. Desde el enfoque de las capacidades, a mayor libertad y capacidad de elección, más bienestar y calidad de vida.

A partir de lo anterior, esta función se evaluó tomando en cuenta las capacidades observadas en el logro de diversos funcionamientos valiosos que previamente se identificaron como parte de su espacio evaluativo, el cual se dividió en cuatro ámbitos: 1) saber/conocer; 2) tener/poder; 3) hacer/realizar; y 4)ser/estar.

Los resultados muestran que en tres de los cuatro ámbitos contrastados existen diferencias significativas $(\mathrm{p}<0.05$; cuadro 7). En el primero se estimó la capacidad en funcionamientos valiosos como conocer el cultivo de maices criollos y sus usos, enseñar a los hijos el cultivo de la tierra, saber hablar purépecha y castellano, entre otros; a partir de estos datos se observa que las comunidades indígenas alcanzan un mayor logro en estos funcionamientos relacionados con el saber/conocer campesino.

Resultados similares se observaron en el ámbito del ser/estar, que se evaluó mediante funcionamientos valiosos como ser cooperativo con la comunidad, ser solidario con otras familias y ser campesino.

De manera diferente, resultó que las comunidades no indígenas tienen una mejor capacidad para lograr funcionamientos valiosos relacionados con el ámbito del poder/tener, como poder enviar a hijos a la escuela, tener una buena vivienda, poder producir sus propios alimentos, o tener otros ingresos no agricolas, entre otros.

De igual modo, en el ámbito del hacer/realizar las comunidades no indígenas registraron un mayor índice de capacidad de logro en aspectos como cultivar para vender, dar trabajo a otras personas y evitar que familiares tengan que migrar; sin embargo, en este ámbito no se observaron diferencias estadísticamente significativas entre los dos grupos de comunidades.

En suma, se puede decir que la capacidad para lograr funcionamientos valiosos relacionados con el plano de lo tangible ( $p o-$ der/tener y hacer/realizar), comparativamente, los alcanzan en grado superior las comunidades no indígenas. En tanto que el logro de funcionamientos valiosos de tipo intangible (como saber/conocer y ser/estar) muestran mejor resultado en las comuni- 


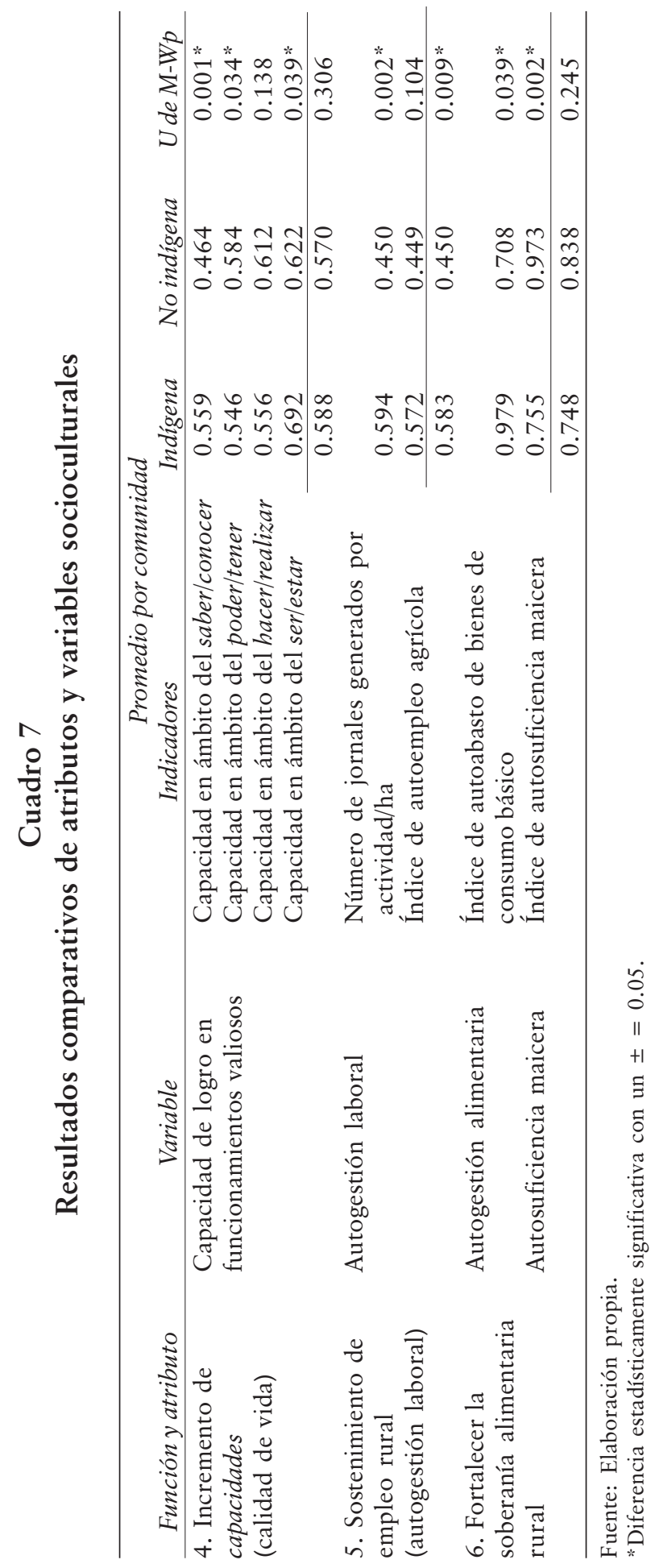


dades de origen indígena; planos que están más próximos a la vida espiritual y al colectivismo de estas comunidades. Tal vez en una concepción alternativa de la cooperación (García Barrios y De la Tejera, 2003: 47) su comportamiento esté siendo guiado por procesos de evaluación normativa y autorreflexión, en donde la normatividad moral y las tradiciones dan lugar a una racionalidad colectiva menos materialista.

En el sentido de Sen, el bienestar sólo es un componente más de la categoría calidad de vida, pues también importa aquello que los individuos logran en función de sus propios objetivos (Appendini et al., 2003: 59). Por ello, tal vez los resultados encontrados en ambos grupos de comunidades correspondan, en efecto, a diferentes percepciones sobre lo valioso, de modo que las comunidades de naturaleza indígena aún preserven un aprecio elevado por cuestiones de orden simbólico y colectivo; mientras que las comunidades no indígenas de esta región, al estar más influidas por la "fuerza uniformizadora de la sociedad y la economía convencionales" (idem), observan un mayor apego por el logro de funcionamientos relacionados con el plano material e individualista del ser. Sin embargo, en esta investigación no se incluye ningún análisis que permita corroborar o contrastar esta sugerencia.

Es importante destacar que el agregado de estos cuatro ámbitos no mostró diferencia estadísticamente significativa ( $p>0.05$; cuadro 7), por lo que no se resuelve si hay más o menos calidad de vida en unas u otras comunidades, pero sí es posible afirmar que hay diferentes calidades de vida y logros entre estas comunidades, lo cual es concluyente en esta fase exploratoria del estudio; queda pendiente para posterior análisis explicar sus causas.

\subsubsection{Función 5: sostenimiento del empleo rural}

Una de las funciones más evidentes de la agricultura, después de su papel central como proveedora de alimentos y materias primas, es su rol en la generación de fuentes de ocupación en el medio rural. Así, en este trabajo definimos la autogestión laboral como el conjunto de acciones internamente generadas por el sistema campesino encaminadas a generar, aprovechar y conservar fuentes de empleo y ocupación (remunerados o no) en el medio rural.

Para medirlas se consideraron dos indicadores. En el primero, número de jornales generados en el cultivo (de 1 ha de maíz), se encontró que las comunidades indígenas emplean más jornales para 


\section{Cuadro 8}

Número de jornales generados por el cultivo de una ha de maíz e índice de autoempleo en la actividad agrícola

\begin{tabular}{llcrc}
\hline \multicolumn{1}{c}{ Indicador } & Comunidad & $\begin{array}{c}\text { Valor } \\
\text { promedio }\end{array}$ & $\begin{array}{r}\text { Desviación } \\
\text { estándar }\end{array}$ & Ude M-Wp \\
\hline Número de jornales & Indígena & 29.72 & 8.37 & $0.002 *$ \\
(1 ha maíz) & No indígena & 22.49 & 10.01 & \\
Índice de autoempleo & Indígena & 0.5725 & 0.3129 & 0.104 \\
agrícola & No indígena & 0.4491 & 0.3328 & \\
\hline
\end{tabular}

Fuente: Elaboración propia.

*Diferencia estadísticamente significativa con un $\pm=0.05$.

esta práctica (29.7 jornales/ha maíz), respecto a las comunidades no indígenas que generan sólo 22.5 jornales (cuadro 8). Aun cuando no se ha realizado un análisis estadístico, es probable que este resultado se relacione con el uso de tracción animal en la preparación del terreno, así como con el control manual de arvenses que se practica en las comunidades indígenas.

El Índice de autoempleo agrícola es el segundo indicador de la autogestión laboral y se calculó a partir del número de jornales propios de la unidad de producción (por ejemplo, no pagados) sobre el número total de jornales empleados para el cultivo de una ha de maíz. En este caso, aunque la diferencia no fue significativa $(\mathrm{p}>0.05)$, también las comunidades indígenas registraron un valor promedio superior para este índice, pues de cada 100 jornales necesarios en estas comunidades, 57.25 los provee directamente la fuerza de trabajo familiar, mientras que en las no indígenas la relación es de al menos 44 por cada 100 jornales (cuadro 8).

Medido en su conjunto como el atributo de la autogestión laboral (cuadro 7), las comunidades indígenas registran un valor más alto con respecto a las no indígenas; esta diferencia sí es significativa $(\mathrm{p}<0.05)$.

\subsubsection{Función 6: fortalecimiento de la soberanía alimentaria en el medio rural}

Nuestra definición de soberanía alimentaria rural se refiere a la capacidad de la unidad productiva campesina para autoabastecerse de los productos básicos y elegir su consumo dentro de una canasta de su preferencia, gusto y calidad. Así, el atributo 
que entraña esta función es la autogestión, operacionalizada con dos índices.

El primero es el indice de autoabasto de bienes de consumo básico con el que se consideró el origen en la provisión de granos, verduras y hortalizas, lácteos, frutas y carnes, ya sea mediante autoabasto o compra (o en su defecto, omisión en su consumo). En los datos comparativos se destaca que en las comunidades indígenas existe un mayor potencial para producir sus propios alimentos básicos ( $\mathrm{p}<0.05$; cuadro 7 ).

Como lo señalan Appendini et al., "frente a la fuerza homogeneizadora de la globalización de los sistemas agroalimentarios" (2003: 55) que implica cambios en la provisión y el consumo de alimentos, se da un proceso de resistencia al desmantelamiento de la seguridad alimentaria de los propios productores agrícolas campesinos basada en su propia estructura productiva. Los resultados del presente estudio corroboran esta afirmación, al encontrar que en el caso de las comunidades indígenas 97.9\% de los productos de una canasta básica se autoabastecen directamente en la unidad productiva, en tanto que para las comunidades no indígenas este porcentaje es de 70.8.

Sin embargo, hay que destacar que este indicador empírico no considera el grado de satisfacción en el consumo sino únicamente la fuente de abasto, por lo que es probable que el autoabasto se logre sobre una base de insatisfacción generalizada. En este sentido es importante intentar construir un indicador que sí tome en cuenta simultáneamente el grado de satisfacción y la calidad de la alimentación.

El indice de autosuficiencia maicera se estimó a partir del balance entre el volumen de maíz producido y el volumen de maíz consumido en la unidad de producción, registrando únicamente el valor dicotómico sí/no es autosuficiente. De esta forma, en el cuadro 7 se observa que $75.5 \%$ de las unidades campesinas indígenas alcanzan la autosuficiencia, mientras que en las comunidades no indígenas este porcentaje se eleva a $97.3 \%$ de las unidades $(\mathrm{p}<0.05)$.

Tal comportamiento es consistente con el hecho de que en las comunidades no indígenas el cultivo de maíz aún se mantiene como una exigua actividad comercial, en el cual se generan excedentes para venderse en los distorsionados mercados locales, principalmente en volúmenes al menudeo que permiten un precio mayor con respecto al precio por tonelada. 
Como sucede en el caso de otros indicadores integradores, al medir el atributo autogestión no se observaron diferencias significativas; esto se explica porque mientras uno de los dos indicadores que ponderan esta variable actúa a favor de un grupo (por ejemplo comunidades indígenas), el otro actúa en su contra, neutralizando el valor conjunto evaluado por la Prueba U de M-W.

\subsection{Multifuncionalidad económica}

Si bien en el tema de la multifuncionalidad generalmente se trata de poner el énfasis en los aspectos ambientales y socioculturales, también existe otro conjunto de roles que aunque estén en la esfera de lo económico no siempre los captura el mercado. Así, en este componente se consideran tres funciones primarias: 7) mantener, ampliar y mejorar la participación de los agentes productivos en el mercado (por ejemplo competitividad); 8) autogestionar recursos materiales e intangibles para la producción; y 9) flexibilizar la capacidad de respuesta y adaptación ante cambios en el sistema.

\subsubsection{Función 7: mantener, ampliar y mejorar la participación del agente productivo en el mercado}

En la teoría económica convencional, uno de los atributos deseables en todo agente económico es la capacidad para mantener o incrementar sostenidamente su posición en el mercado por medio de la producción, distribución y venta de bienes y servicios en el tiempo, lugar y forma solicitados por éste; a ello se le llama competitividad (Rojas et al., 2001: 31).

En el caso del sistema de producción campesina en estudio, esta función se estimó tomando en cuenta dos variables directamente asociadas a la competitividad convencional: la rentabilidad y la productividad.

La primera se calculó integrando dos índices: 1) la tasa beneficio/costo, considerando el total beneficio (valor de productos, subproductos, subsidios, etc.), sobre el costo real de la producción como costos pagados y no pagados); y 2) el porcentaje vendible de la producción de maíz.

En el cuadro 9 se indica que en ambos índices las comunidades no indígenas alcanzan niveles superiores, por lo que la rentabilidad de la actividad maicera es, en un grado de significancia estadística, superior en estas comunidades con respecto a las indígenas. 


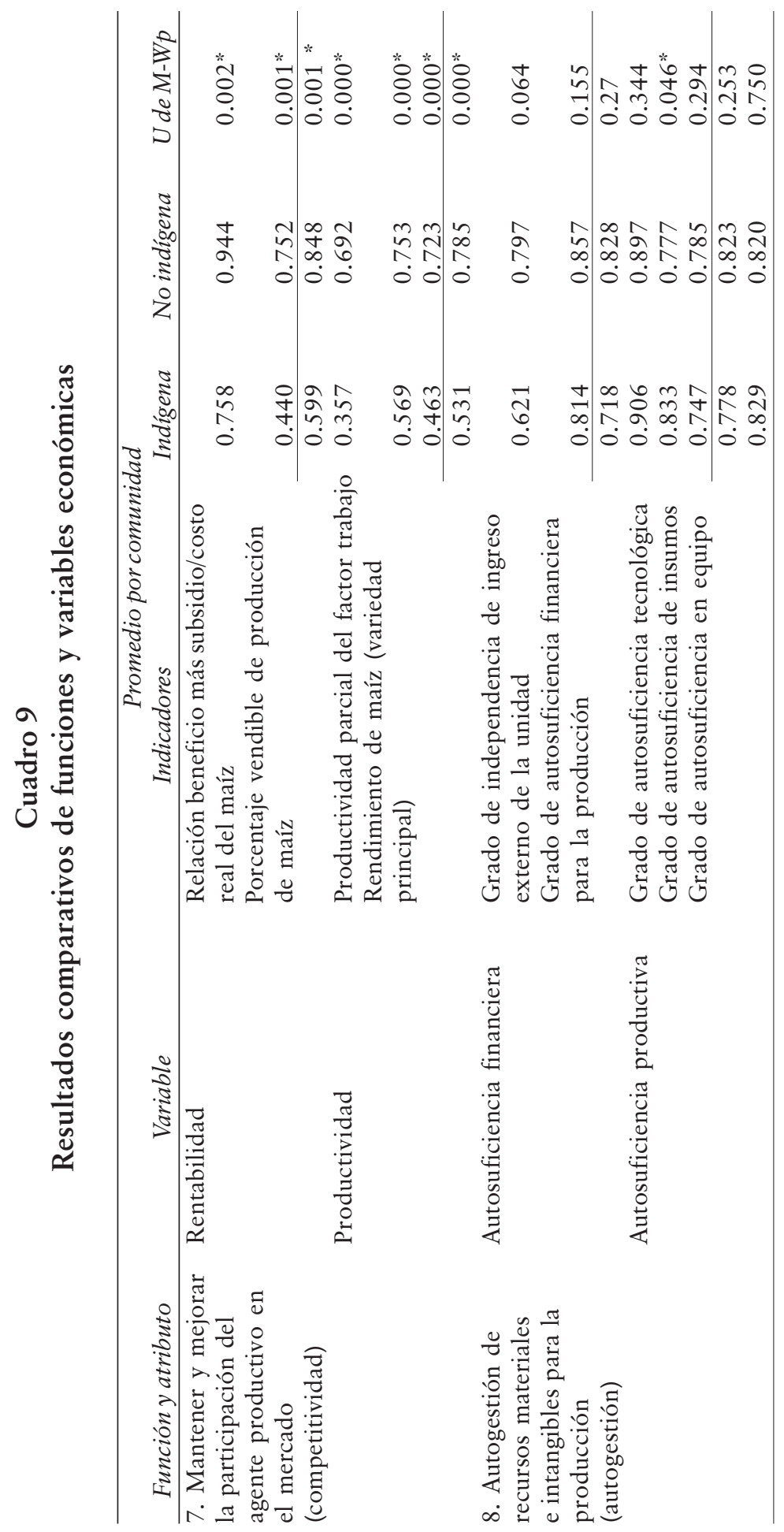




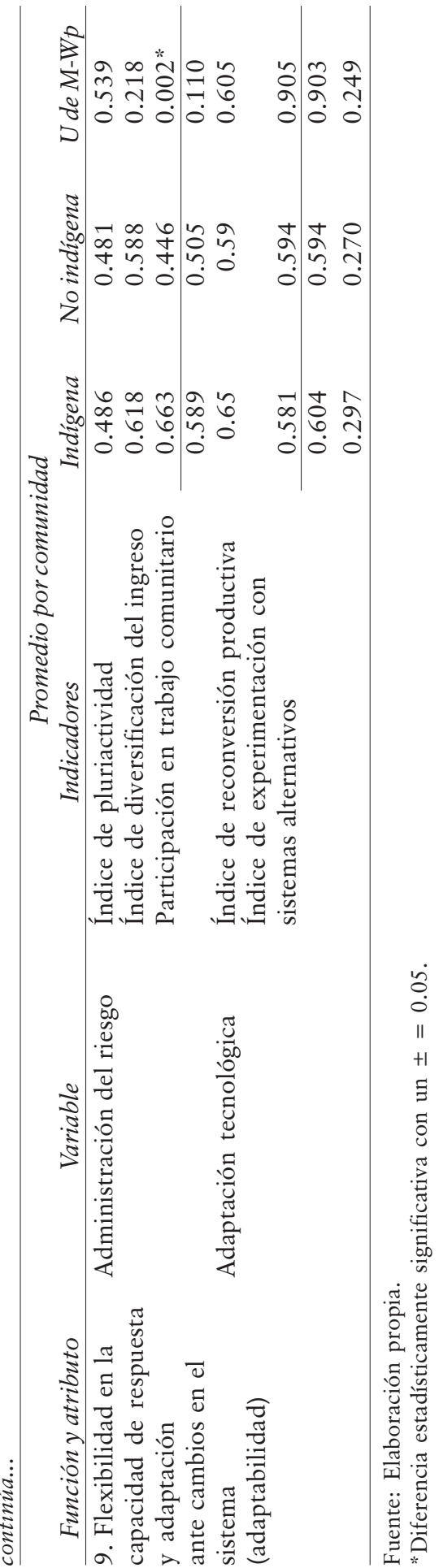


De igual modo, la productividad se estimó considerando dos componentes: 1) la productividad parcial del factor trabajo (rendimiento/número de jornales empleados/ha de maíz); y 2) el rendimiento medio por ha de maiz. Los resultados se muestran en el cuadro 10.

\section{Cuadro 10 \\ Productividad del factor trabajo y rendimiento de maíz}

\begin{tabular}{llccc}
\hline \multicolumn{1}{c}{ Indicador } & Comunidad & $\begin{array}{c}\text { Valor } \\
\text { promedio }\end{array}$ & $\begin{array}{c}\text { Desviación } \\
\text { estándar }\end{array}$ & Ude M-Wp \\
\hline $\begin{array}{l}\text { Productividad del } \\
\text { factor trabajo }\end{array}$ & Indígena & 44.73 & 22.641 & $0.000^{*}$ \\
$\begin{array}{l}\text { (kg/jornal) } \\
\text { Rendimiento de }\end{array}$ & Indígena & 1.195 & 422.882 & $0.002 *$ \\
maíz(ton/ha) & No indígena & 1.583 & 667.015 & \\
\hline
\end{tabular}

Fuente: Elaboración propia.

"Diferencia estadísticamente significativa con un $\pm=0.05$.

Destaca el valor comparativamente alto que se observa en la productividad del factor trabajo, pues mientras que en el caso de las comunidades indígenas el promedio de este indicador es de $44.74 \mathrm{~kg} /$ jornal, en el caso de las comunidades no indígenas es casi del doble $(86.52 \mathrm{~kg} /$ jornal).

Este resultado se atribuye sobre todo a las prácticas agrícolas acostumbradas en las primeras comunidades, pues en ellas todavía son bastante frecuentes las labores manuales de limpieza y chaponeo, que demandan mucha mano de obra.

Por su parte, en promedio el rendimiento de maíz es más alto $(\mathrm{p}<0.05)$ en las comunidades no indígenas que en las autóctonas, con valores de 1,195 ton/ha y 1,583 ton/ha, respectivamente; este resultado se relaciona con el paquete tecnológico empleado en estas comunidades no indígenas, el cual utiliza sobre todo insumos agroquímicos con efectos positivos sobre el rendimiento en el corto plazo, pero fuertemente degradantes del entorno en el mediano plazo.

Los valores observados en los cuatro indicadores anteriores (cuadro 9) sugieren que sí hay diferencias en las prácticas agrícolas empleadas en unas y otras comunidades, pues se registra una mayor competitividad convencional en las unidades de producción campesina no indígenas $(\mathrm{p}=0.000)$. No obstante, es importante señalar que para el caso del estudio que realizaron en España Kallas y Gómez-Limón (2005: 13), esta función no 
fue muy valorada por la sociedad, obteniendo un peso relativo de $0.0 \%$ con la técnica del proceso analítico jerárquico (analytical hierarchy process)

\subsubsection{Función 8: autogestión de recursos materiales e intangibles para la producción}

La autosuficiencia económica subyace aquí como atributo que le da valor y sentido a la función de autogestión de los recursos para la producción. Esta autosuficiencia comprende, por un lado, el componente financiero y, por otro, el componente productivo (véase el Anexo 2).

El primero se calculó a partir de dos índices: 1) indice de independencia de ingreso externo de la unidad, que es el inverso entre el monto total del ingreso proveniente de fuentes externas a la unidad (como subsidios, remesas, etc.) sobre el ingreso total; y 2) el indice de autosuficiencia financiera para la producción, que considera la fuente del financiamiento, por ejemplo, para la preparación del terreno, la siembra, la adquisición de insumos, el laboreo, etc. Sin alcanzar niveles estadísticamente significativos, en ambos indicadores las comunidades no indígenas mostraron valores promedio más altos (cuadro 9).

En particular, es importante mencionar que el índice de independencia de ingreso externo de la unidad muestra que en el caso de las comunidades indígenas, 62 centavos de cada peso que ingresa a la unidad productiva los genera internamente la misma unidad (38 centavos provienen de fuentes externas). Mientras en el caso de las comunidades no indígenas la dependencia de fuentes externas es menor, pues de cada peso sólo 20.3 centavos no se generan internamente, sino que provienen de subsidios, remesas, etcétera.

Por otro lado, en el atributo de la autosuficiencia económica también se estimó el grado de autosuficiencia productiva considerando tres ámbitos: 1) tecnológico (conocimiento y práctica agrícola); 2) insumos (semilla, abono, control de arvenses, fertilizante, etc.); y 3) implementos (maquinaria y equipo).

En los primeros dos componentes se encontraron valores superiores para la muestra extraída de las comunidades indígenas, aunque con diferencia significativa sólo para el caso de los insumos ( $\mathrm{p}<0.05$; cuadro 9). El componente equipo e implementos obtuvo un valor ligeramente mayor para las observaciones de las comunidades no indígenas, sin que sea significativo. 
Como sucedió en el caso de otros atributos, la integración de los componentes de la autosuficiencia económica no mostró diferencias entre los grupos comparados, dada la neutralización que ocurre entre ellos al ponderarse en un mismo indicador.

\subsubsection{Función 9: flexibilidad y capacidad de respuesta ante cam- bios en el sistema}

La adaptabilidad hace referencia a la capacidad del sistema para responder y amoldarse a nuevas condiciones del entorno económico y biofísico mediante procesos de innovación, aprendizaje y uso de opciones múltiples, lo cual puede lograrse mediante la administración del riesgo y propiciando la adaptación tecnológica.

De este modo se incluyeron dos variables para medir el grado de adaptabilidad del sistema de producción campesino. En primer lugar se considera la administración del riesgo, calculada empíricamente a partir de tres índices: 1) indice de pluriactividad de la unidad productiva, que es el número de actividades productivas realizadas por la unidad sobre una base de 10 , número máximo de actividades diversas identificado en la muestra; 2) el indice de diversificación del ingreso; y 3) el grado e participación en el trabajo comunitario, considerado como parte de la economía moral del sistema, mismo que se calculó a partir de la participación de la unidad en trabajos no pagados para la comunidad (faenas), la iglesia, así como en el sistema de mano vuelta o trabajo cooperativo, el cual se ponderó sobre una base máxima de uno.

$\mathrm{Al}$ realizar las pruebas comparativas, en los tres índices hubo valores superiores en la muestra proveniente de las comunidades indígenas; sin embargo, estas diferencias sólo fueron significativas en el caso del trabajo comunitario, lo cual refleja la tradición señalada que aún se conserva en las localidades autóctonas para participar en los trabajos cooperativos.

En particular se debe destacar la buena consistencia y solidez estadística que demostró el índice de diversificación del ingreso aquí propuesto y diseñado, al considerar tanto el número de fuentes generadoras de ingreso como la proporcionalidad aportada por cada una de ellas; así, a mayor diversificación y más equidad en el ingreso generado por cada fuente, el riesgo es menor pues disminuye la dependencia hacia una fuente de ingreso predominante.

A la segunda variable considerada en el atributo de la adaptabilidad se denominó adaptación tecnológica, cuya estimación incluyó dos variables dicotómicas: 1) reconversión tecnológica (du- 
rante los últimos tres años) y 2) experimentación con sistemas o técnicas de producción alternativas, poniendo como ejemplo a la agricultura orgánica, en este caso particular.

La reconversión productiva se reportó en $65 \%$ de las unidades indígenas de producción campesina, mientras que en las no indígenas el porcentaje fue de 59\%. Para la experimentación con sistemas alternativos de cultivo, como la agricultura orgánica, el porcentaje fue proporcionalmente el mismo: $58.1 \%$ y $59.4 \%$ para las muestras indígena y no indígena, respectivamente. Estas diferencias no fueron significativas (cuadro 9).

Se debe señalar que en las cuatro comunidades estudiadas se incluyó la aplicación de la encuesta a unidades de producción que han experimentado con el uso de insumos alternativos, como la lombricomposta, el guano de murciélago y el abono de corral, en sustitución de los fertilizantes comunes de origen inorgánico; sin embargo, se observó que en la gran mayoría de los casos esta experimentación se hace en principio para disminuir los costos de producción, y después para reducir los efectos negativos de la agricultura sobre los recursos agrícolas. El análisis comparativo de estos grupos de productores se analizará en un trabajo posterior.

Una vez más, la integración de los índices que componen el atributo evaluado hizo que las diferencias particulares se diluyeran, lo que mostró un comportamiento de la variable adaptabilidad estadísticamente similar en los grupos de comparación (cuadro 9).

\subsection{Multifuncionalidad de la agricultura campesina}

Con el objetivo de desarrollar un indicador que integrara el valor individual de cada una de las funciones aquí consideradas como parte de MFA campesina de la Meseta Purépecha, las variables incluidas en cada plano (ambiental, sociocultural y económica) se ponderaron de manera proporcional (Anexo 2) para dar lugar a un indicador específico por cada uno de ellas. A su vez, estos tres planos se ponderaron equitativamente para crear el indicador que denominamos multifuncionalidad de la agricultura campesina.

Los resultados se presentan en el cuadro 11, donde destaca que sí existen diferencias significativas entre los componentes de la multifuncionalidad ambiental y económica, y son las comunidades indígenas las que registran un valor más alto en el primer caso, mientras que en comunidades no indígenas es superior 


\section{Cuadro 11}

Multifuncionalidad de la agricultura campesina en la Meseta Purépecha

\begin{tabular}{llccc}
\hline \multicolumn{1}{c}{ Concepto } & \multicolumn{4}{c}{ Promedio por comunidad } \\
\hline Multifuncionalidad & Categoría & Indígena & No indigena & U de M-Wp $p$ \\
de la agricultura & Sociocultural & 0.613 & 0.522 & $0.008 *$ \\
campesina & Económica & 0.631 & 0.576 & 0.233 \\
& & 0.477 & 0.642 & $0.000 *$ \\
\hline
\end{tabular}

Fuente: Elaboración propia.

"Diferencia estadísticamente significativa con un $\pm=0.05$.

\section{Figura II}

\section{Componentes de la MFA campesina en la Meseta Purépecha según tipo de comunidad}



Fuente: Elaboración propia.

el valor del componente económico. Con respecto al componente sociocultural, sin llegar a ser significativo, también se observa un valor superior en el caso de las comunidades indígenas.

De modo similar a lo observado en la integración de los atributos del sistema, cuando se agruparon los tres componentes en torno al indice de multifuncionalidad de la agricultura campesi$n a$, las diferencias entre los grupos comparados quedaron ocultas por su mutuo efecto neutralizador dada la magnitud y el sen- 
tido de los valores, que se reflejó en la baja significancia estadística $(\mathrm{p}>0.05)$.

Por esta razón se optó por utilizar un método de análisis mixto denominado amiba para considerar conjuntamente los efectos particulares de cada una de las funciones, los atributos y las variables incluidas en este sistema, lo que permite tener una visión gráfica comparativa de esta totalidad.

En la figura II se observa cómo las variables que corresponden a la multifuncionalidad ambiental y sociocultural muestran indicadores de desempeño mayores para las comunidades indígenas, a diferencia de las no indígenas (variables 1 a 12, 17 y 18). En tanto que éstas últimas comunidades reportaron sobre todo un mejor resultado en las variables que forman parte de la multifuncionalidad económica (variables 11, y 13 a 16).

\section{Conclusiones}

Este trabajo parte del principio que la agricultura es una actividad compleja en la cual la producción de alimentos, fibras y otras materias primas son solamente su parte más conspicua y que existen otros bienes públicos y externalidades generadas conjuntamente con la actividad agrícola. Los resultados aquí analizados confirman la existencia del carácter multifuncional de la agricultura campesina en el caso de la Meseta Purépecha, Michoacán.

El instrumental metodológico propuesto permitió identificar y describir una serie de atributos considerados relevantes en la conformación de la multifuncionalidad: diversidad, sustentabilidad, autosuficiencia, autogestión, calidad de vida, competitividad y adaptabilidad; lo cuales dan cuerpo y cumplimiento a diversos roles asociados a la actividad agrícola.

Agrupar estas múltiples funciones en tres planos es, en efecto, una clasificación artificial, pero que permite identificar áreas donde determinados productores con características peculiares (como campesinos indígenas y no indígenas) llegan a tener mejor desempeño (por ejemplo, mayor provisión de bienes públicos y externalidades ambientales, socioculturales y económicas positivas). Este hecho se destaca puesto que desde la perspectiva de la producción conjunta de la agricultura se observa que ciertas funciones del sistema se asocian preferentemente con la producción del maíz, como el bien básico o central que constituye la motivación principal de esta actividad productiva. 
En esta investigación se encontró que en la variación de la producción conjunta de estos bienes no centrales importa no sólo cuál es el producto central, sino la forma en la que se desarrolla el proceso productivo para su obtención. Así se identificó, por ejemplo, que funciones como la preservación de la biodiversidad, el sostenimiento de la diversidad agroambiental, la conservación genética del maíz, la sustentabilidad de la unidad productiva y la autosuficiencia energética (todas del plano ambiental) se asocian más a la forma de producción campesina tradicionalmente desarrollada en comunidades indígenas, donde el maíz tal vez es visto como un sistema generador de bienes múltiples.

En contraste, en la producción campesina de comunidades no indígenas se observó que el maíz se considera esencialmente un bien comercial, al cual se asocian funciones como la autosuficiencia maicera, la rentabilidad económica, la productividad convencional y la autosuficiencia financiera, que pertenecen al plano económico de la multifuncionalidad.

En general, el conjunto de indicadores propuestos para evaluar los componentes de la multifuncionalidad mostraron suficiente solidez estadística y sensibilidad al cambio, por lo que se pueden considerar apropiados. En particular se deben destacar tres aportaciones metodológicas realizadas con este trabajo: 1) el desarrollo de un método de valoración contingente para estimar la oferta de bienes sin mercado, en este caso aplicado a la disposición a sembrar maíz criollo; 2) un método para aproximarnos a medir calidad de vida y bienestar mediante el diseño del indice de capacidad de logro en funcionamientos valiosos; $\mathrm{y}$ 3) un método para conocer el riesgo en el ingreso, por medio del índice de diversificación del ingreso, el cual se puede aplicar a diversos ámbitos de la socioeconomía.

Por otra parte, también se aporta evidencia empírica en el sentido de que a pesar de la reducida dimensión comercial de las unidades de producción campesina, éstas juegan un importante papel en el sostén de las áreas rurales; de hecho, se puede considerar que tales unidades campesinas son más importantes por el mantenimiento del empleo, el arraigo de la población al campo, la preservación de la agrodiversidad y los recursos naturales y la viabilidad del medio rural, que por su contribución al volumen y el valor de la producción agrícola.

Estas múltiples funciones bien podrían denominarse servicios campesinos por el carácter de prestación o realización de una actividad que provee beneficios a terceros, y desde esta perspec- 
tiva, ameritan que se desarrollen esquemas de compensación y retribución más justos y que incentiven la provisión de dichos bienes públicos.

El caso de la Meseta Purépecha central es aleccionador como estudio de caso sobre la MFA campesina. Ahí es posible encontrar una tipología diversa de productores que en su mayoría se siguen esforzando en mantener la producción de maíz como actividad principal y base para la realización de otras labores agropecuarias y forestales, complementarias del ingreso familiar.

El presente estudio es de naturaleza eminentemente exploratoria y descriptiva, por lo que no se enfatizó en evaluar los grados de asociación entre las variables y los componentes del sistema estudiado. Sin embargo, los datos de esta investigación sugieren que la MFA campesina encuentra mejores condiciones para su desarrollo en el caso de comunidades tradicionales como las indígenas, en las cuales aún se preservan ciertas costumbres, prácticas, normas y otras instituciones locales que fomentan los esquemas de cooperación y de reciprocidad, base de la multifuncionalidad sociocultural y, en sí, del capital social de estas comunidades.

Sin embargo, es importante no idealizar a las comunidades indígenas como el modelo de agricultura multifuncional a seguir. En esta comparación dichas comunidades obtuvieron registros más altos en la mayoría de las variables y atributos analizados, pero queda pendiente examinar si este comportamiento lo determina un propósito específico hacia el logro de objetivos múltiples a partir de su propia concepción sobre la relación agricultura-campesino-naturaleza; o bien, si es producto de su actividad en un contexto de insuficiencia de recursos para la vida productiva y falta de acceso a otras fuentes de ingreso no agrícola, que los atrapa en el umbral de la pobreza y los impulsa hacia la multifuncionalidad. 


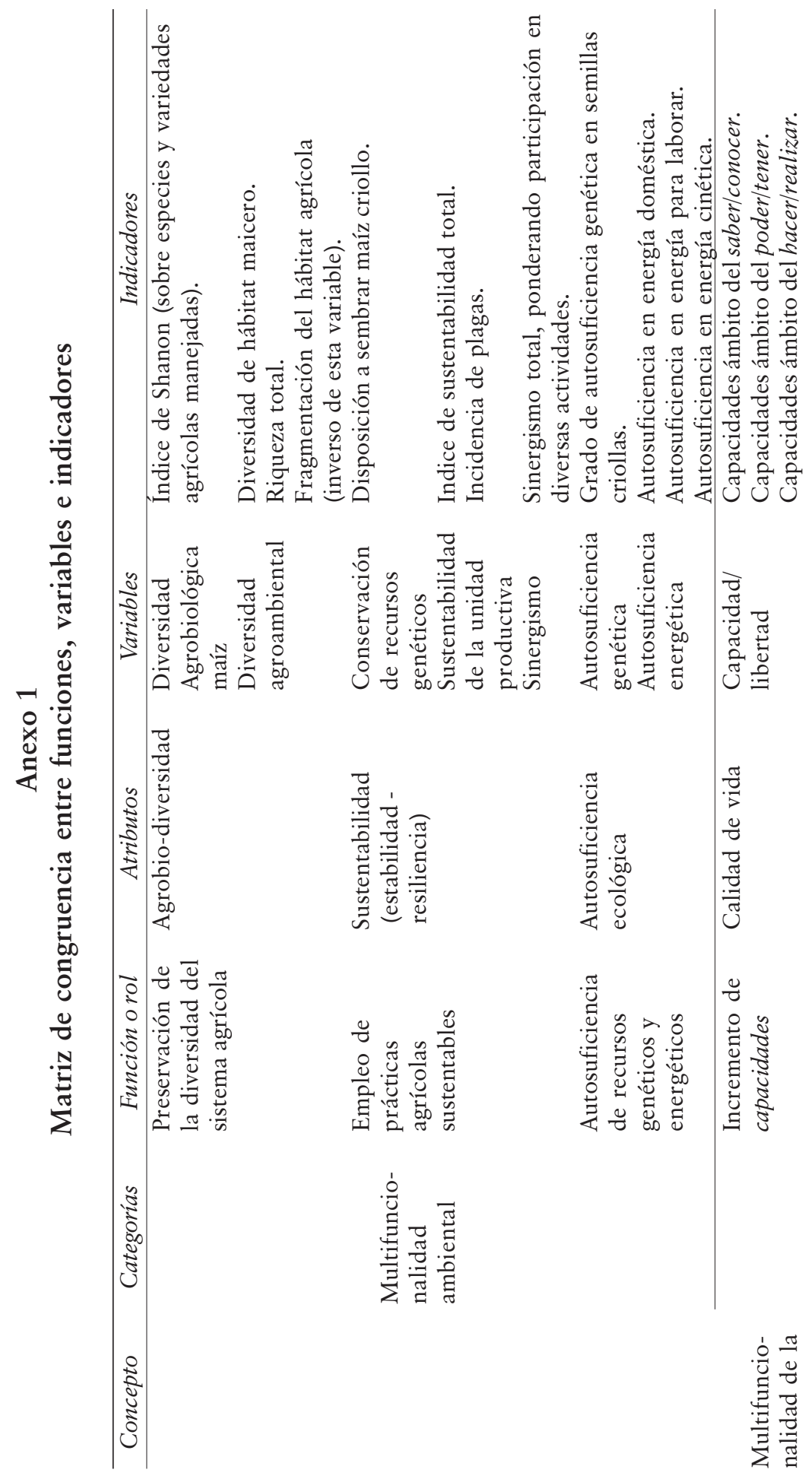




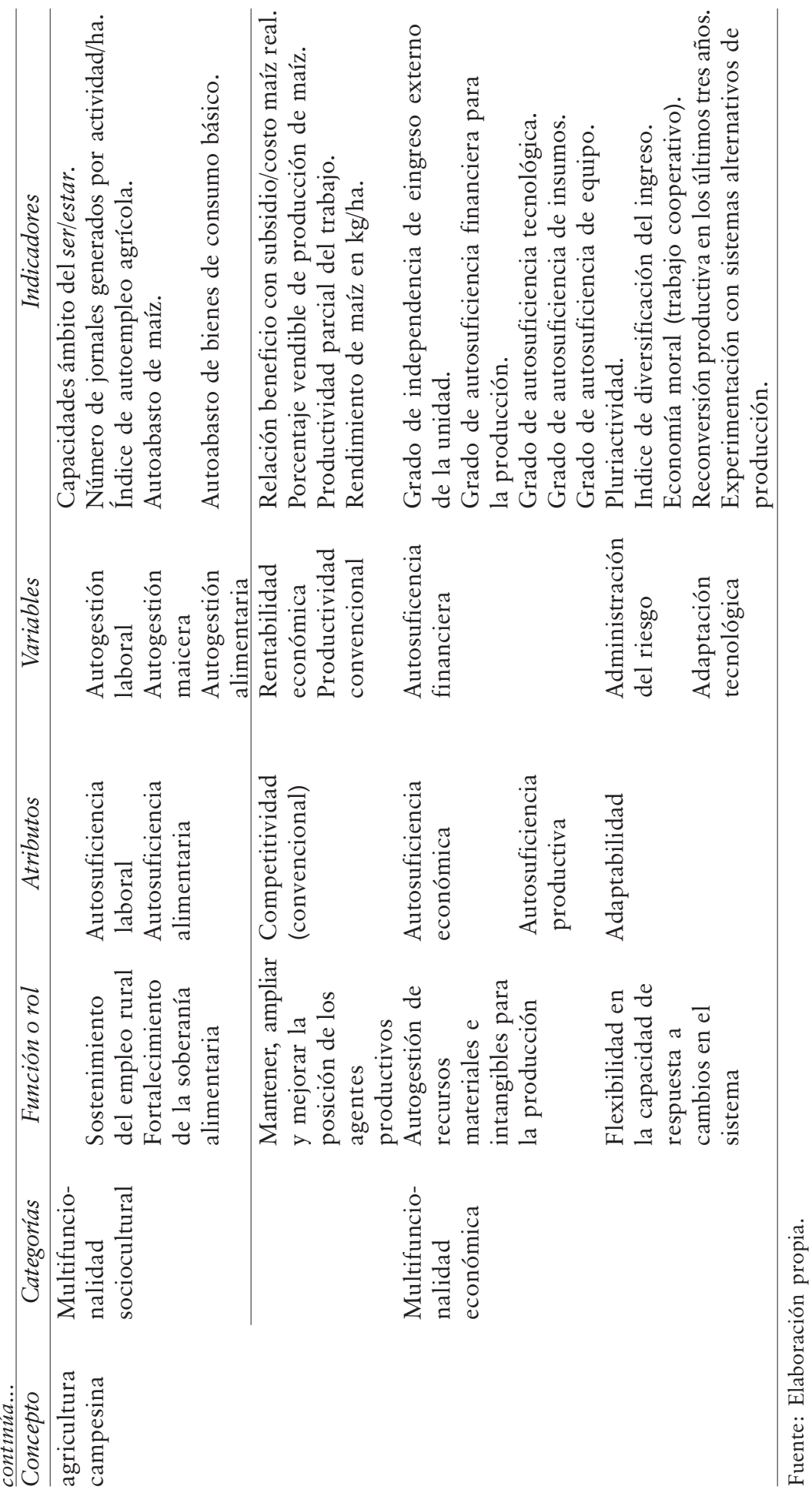




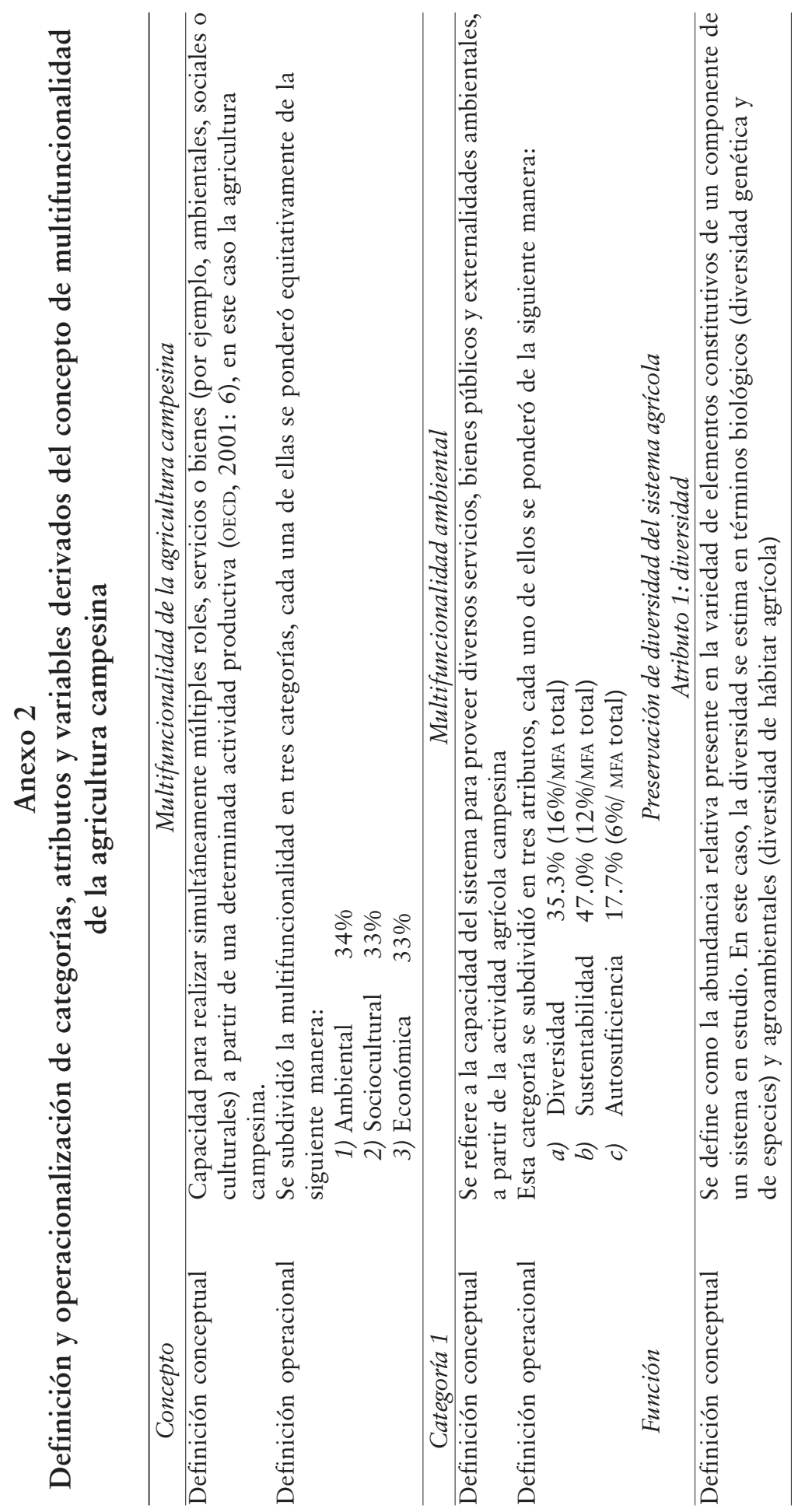




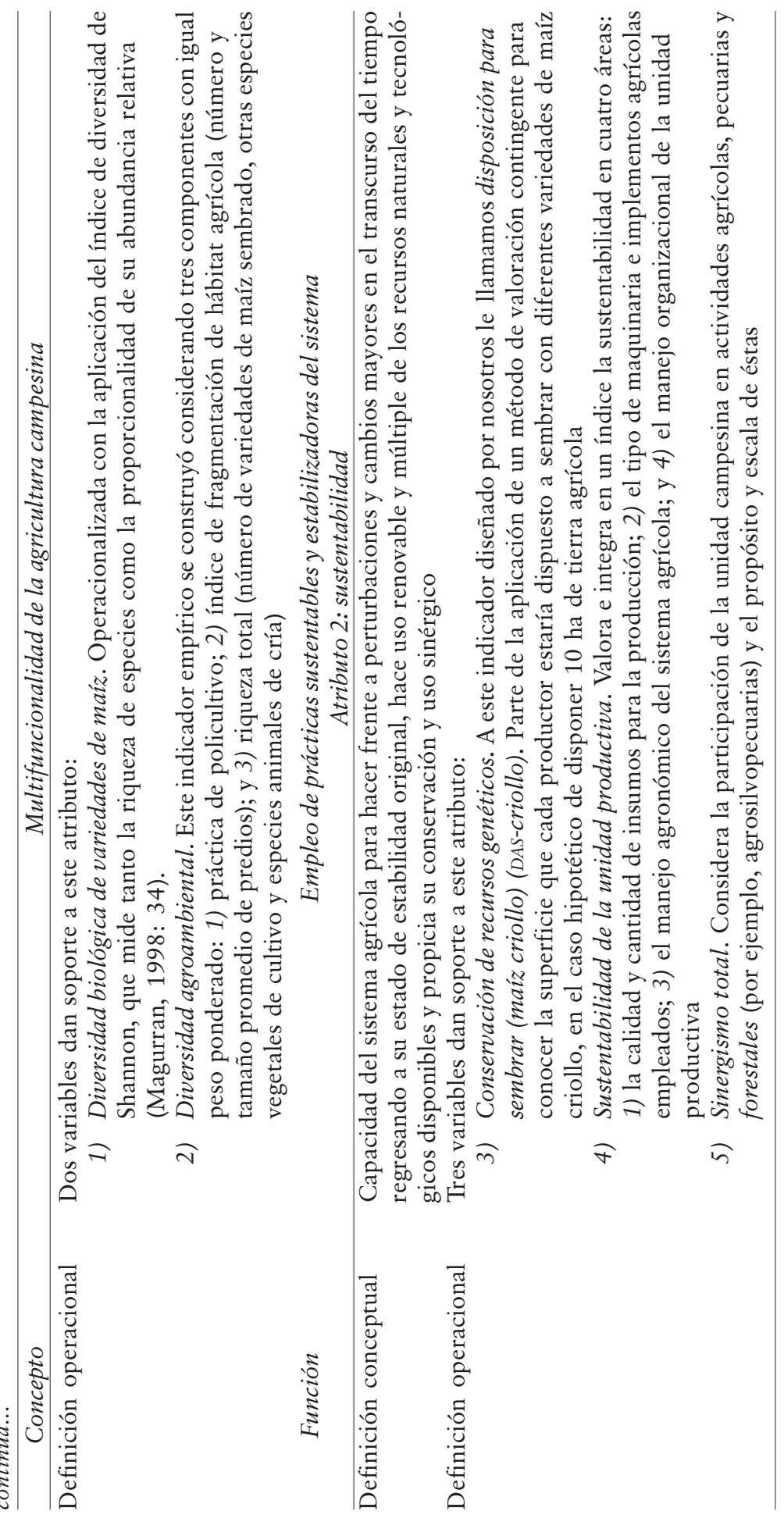




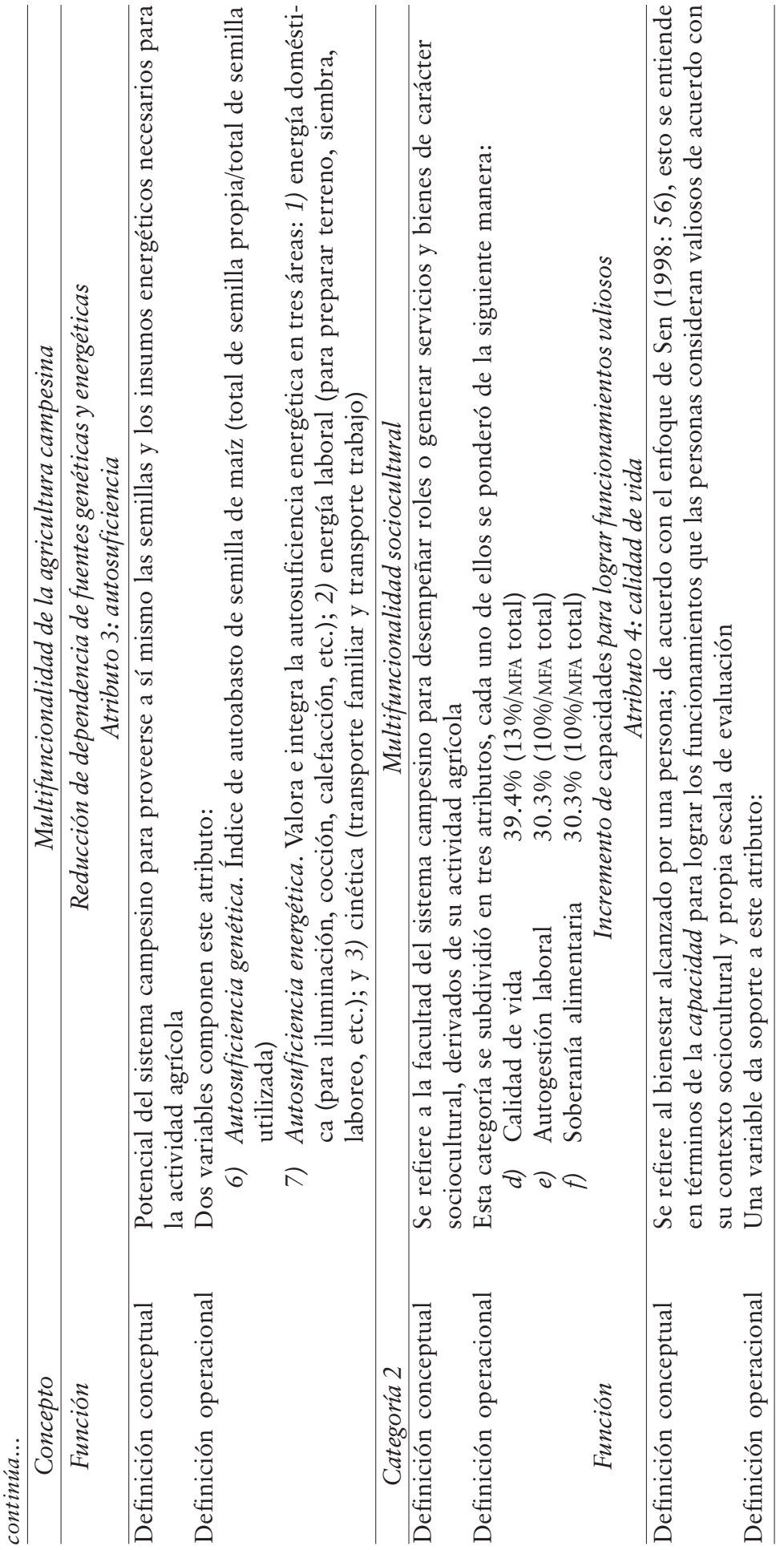




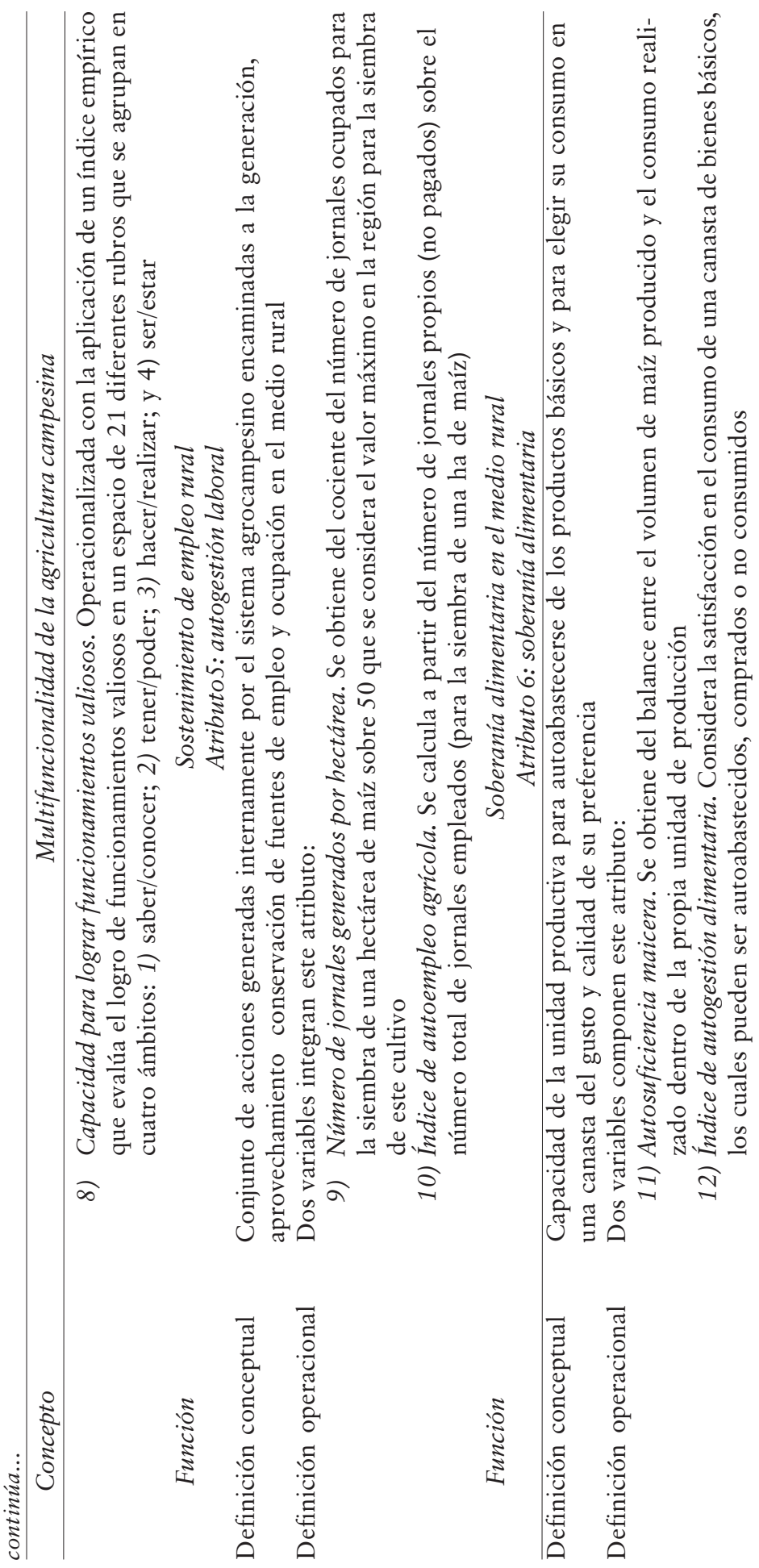




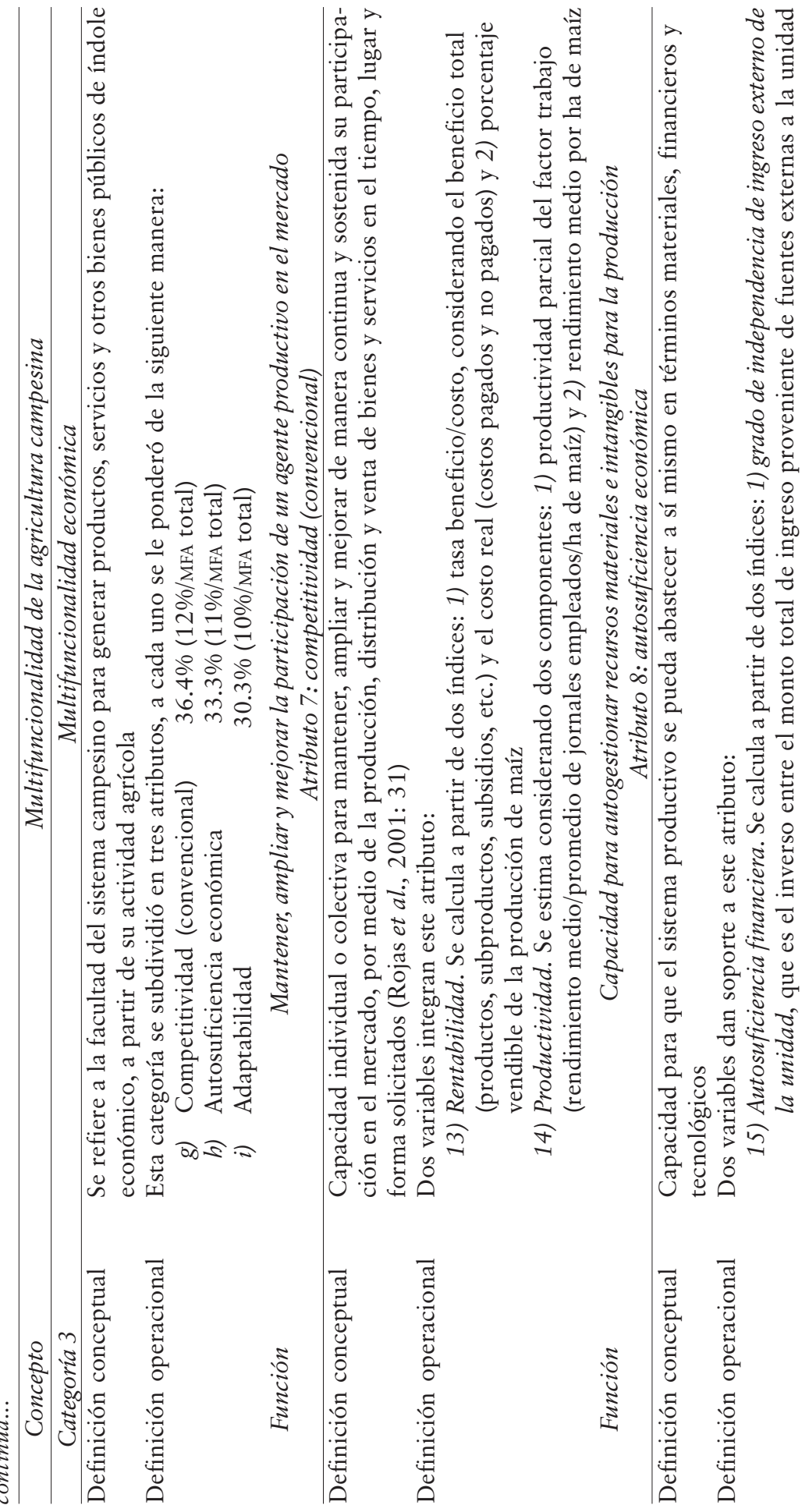




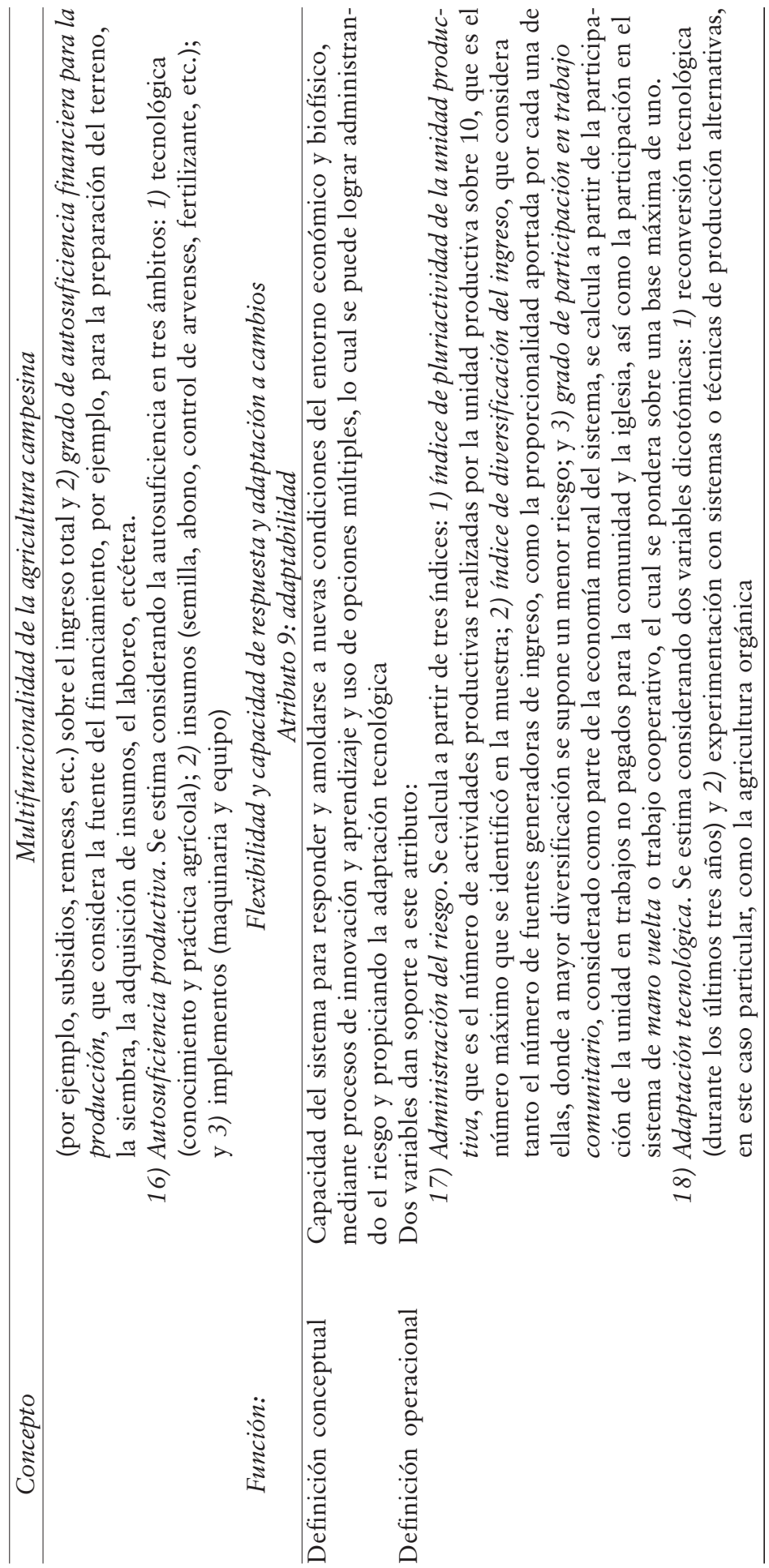




\section{Bibliografía}

Alarcón-Chaires, Pablo (2001), Ecología y transformación campesina en la Meseta Purépecha. Una tipología socioecológica de productores rurales de Nahuatzen, Michoacán, Universidad Michoacana de San Nicolás de Hidalgo, Morelia.

Appendini, Kirsten, Beatriz de la Tejera y Raúl García Barrios (2003), "La seguridad alimentaria en México en el contexto de las nuevas relaciones comerciales internacionales”, en Beatriz de la Tejera (coord.), Dimensiones del desarrollo rural en México, Universidad Autónoma Chapingo-Centro de Investigaciones y Desarrollo del Estado de Michoacán-Secretaría de Urbanismo y Medio Ambiente del Gobierno de Michoacán, México, pp. 53-74.

Ayala-Ortiz, Dante Ariel (2007), "Entre la crisis y la reestructuración: la paradoja de la agricultura campesina en México", tesis de doctorado, CIESTAAM-Universidad Autónoma Chapingo.

Beals, Ralph Larson (1992), Cherán: un pueblo de la sierra tarasca, El Colegio de Michoacán, Zamora.

Crecente, Rafael (2002), "Ordenación del espacio rural como instrumento de la multifuncionalidad", Jornada Autonómica de Galicia, España, http:/www.libroblancoagricultura. com/libroblanco/jautonómica/galicia/ponencias/crecente/ crecente3.asp.

Escobar M., Darío A., Jorge Romero P., Jorge A. Agustín, Miriam A. Núñez V., Javier Vence G. y Darío Rivera M. (1997), Las regiones agrícolas de Michoacán, Universidad Autónoma Chapingo-Centro Regional Universitario Centro-Occidente, México.

García-Barrios, Raúl y Beatriz de la Tejera (2003), “Cooperación económica y tradición: del optimismo tecnocrático al optimismo humanista", en Beatriz de la Tejera (coord.), Dimensiones del desarrollo rural en México, Universidad Autónoma Chapingo-Centro de Investigaciones y Desa- 
rrollo del Estado de Michoacán-Secretaría de Urbanismo y Medio Ambiente del Gobierno de Michoacán, México, pp. 33-52.

Geilfus, Frans (1997), 80 herramientas para el desarrollo rural participativo: diagnóstico, planificación, monitoreo, evaluación, IICA-SAGAR, México.

Hagedorn, Konrad (2005), "The role of integrating institutions for multifuncionality", EAAE Congress 2005, Copenhagen, http://www.eaae2005.dk/ ORGANISED_SESSION_PAPERS/OS4/737_hagedorn.pdf.

Kallas, Zein y José Antonio Gómez-Limón (2005), “Multifuncionalidad de la agricultura y política agraria: una aplicación al caso de Castilla y León”, Universidad de Valladolid, España.

Losch, Bruno (2002), “The multifunctionality of agriculture and the challenge for farming in the South: a new foundation for public policies?", sFER Meeting The multifunctionality of agricutural activity and its recognition by public policies, 21 y 22 de marzo, París.

Magurran, Anne E. (1988), Ecological Diversity and its Measurement, Princeton University Press, New Jersey, pp. 7-47.

Masera, Omar, Marta Astier y Santiago López-Ridaura (2000), "El marco de evaluación MESMIs", en Omar Masera y Santiago López-Ridaura (eds), Sustentabilidad y sistemas campesinos: cinco experiencias de evaluación en el México rural, GIRA, A.C., México, pp. 13-46.

Mendenhal, William y James E. Reinmuth (1999), Estadística para administración y economía, Grupo Editorial Interamericano, México.

OECD (Organization for Economic Co-operation and Development) (2001), Multi-functionaliy: Towards an Analytical Framework, OECD, París. 
OECD (Organization for Economic Co-operation and Development) (2003), Multi-functionaliy: the policy implicatio$n s$, OECD, París.

Rojas, Patricia, Hugo Chavarría y Sergio Sepúlveda (2001), “Competitividad y cadenas agroalimentarias: una definición conceptual”, en Patricia Rojas, Hugo Chavarría y Sergio Sepúlveda (comps.) Competitividad, cadenas agroalimentarias y territorios rurales: elementos conceptuales, Instituto Interamericano de Cooperación para la Agricultura, San José, pp. 29-57.

Romero-Peñaloza, Jorge (1995), “Configuración agrícola regional y zonas agrícolas”, en S. Pulido, P. Romero y V. Núñez (eds.), La producción agropecuaria y forestal de la región Sierra Purépecha, Michoacán, Universidad Autónoma Chapingo, pp. 69-82.

Sagarpa (Secretaría de Agricultura, Ganadería, Pesca y Alimentación) (2003), Acuerdo Nacional para el Campo, Gobierno de la República, México.

Sen, Amartya (1998), “Capacidad y bienestar”, en Martha Nussbam y Amartya Sen (comps.), La calidad de vida, Fondo de Cultura Económica, México, pp. 54-79.

Valdés, Alberto y William Foster (2004), Externalidades de la agricultura chilena. Sintesis del estudio ROA para Chile, http:/ /www.rimisp.org.seminariotrm/doc/valdes-y-foster.pdf.

Recibido: 29 de agosto de 2007. Reenviado: 9 de febrero de 2009. Aceptado: 16 de febrero de 2009.

Dante Ariel Ayala Ortiz. Es doctor en economía agroindustrial por la Universidad Autónoma Chapingo; maestro en integración regional y desarrollo sustentable por la Universidad de Roskilde, Dinamarca; y biólogo y economista por la Universidad Michoacana de San Nicolás de Hidalgo. Actualmente es profesor-investigador titular en la Facultad de Economía de la Universidad Michoacana, adscrito a la División de Estudios de Posgrado. Sus 
líneas de investigación son: multifuncionalidad de la agricultura campesina, valoración ambiental económico-ecológica, políticas agroambientales y desarrollo local. Es miembro del Sistema Nacional de Investigadores (SNI), nivel I. Entre sus últimas publicaciones destacan: "México y Estados Unidos. Análisis comparativo de dos crisis agrícolas", Espiral, XII (34) México, pp. 125-146 (2005); en coautoría, "Determinantes de la autosuficiencia del maíz en México: un modelo econométrico de ecuaciones simultáneas", Economía y Sociedad, 17, Universidad Michoacana de San Nicolás de Hidalgo, México, pp. $73-94$ (2006); en coautoría, "La ecocondicionalidad como instrumento de política agrícola para el desarrollo rural sustentable en México", Gestión y Política Pública, XVII (2), Centro de Investigación y Docencia Económicas, México, pp. 315-353 (2008).

José Raúl García Barrios. Es doctor en economía agrícola y recursos naturales por la Universidad de California, en Berkeley; maestro en economía por El Colegio de México y biólogo por la Universidad Nacional Autónoma de México. Fue investigador del Centro de Investigación y Docencia Económicas y actualmente lo es del Centro Regional de Investigaciones Multidisciplinarias de la Universidad Nacional Autónoma de México. Desde 1994 es miembro del Sistema Nacional de Investigadores (SIN) nivel I. Sus líneas de investigación actuales se relacionan con la restauración ecológica en cuencas y con el estudio de microinstituciones económicas del espacio rural. Desde hace varios años coordina un proyecto de rescate integral de ríos, bosques y barrancas en el estado de Morelos. Es autor de Lagunas: deterioro ambiental y tecnológico en el campo semiproletarizado, El Colegio de México, México (1991). Entre sus publicaciones recientes se encuentran: "Rescatando El Salto de San Antón: una historia reciente de construcción institucional", Economía Mexicana, nueva época 3(2), CIDE, México pp. 225-285 (2007); en coautoría, "La sociedad controlable y la sustentabilidad", en Martha Astier, Omar Masera y José Galván (eds.), Temas de frontera en evaluaciones de sustentabilidad, Mundiprensa, México, pp. 213246, (2006); en coautoría, "Riesgos económicos de la apertura a transgénicos en el mercado del maíz en México", Reporte de Investigación del CIESTAAM, 77, Universidad Autónoma Chapingo (2006). 